\title{
EFICIENNCIA DO DELINEAMENTO COMPOSTO CENTRAL ORTOGONAL COM 15 PONTOS EM RELAÇÃO AO DELINEAMENTO DUPLO COMPOSTO CENTRAL ORTOGONAL COM 29 PONTOS
}

\author{
ADA CASTELLARI
}

Orientador: Dr. CLÓVIS POMPÍLIO DE ABREU

Dissertação apresentada à Escola Superior de Agricultura "Luiz de Queiroz", da Universidade de São Paulo, para obtenção do título de Mestre em Agronomia. Área de concentração: Estatística $\theta$ Exporimentação Agronômica.

PIRACICABA

Estado de São Paulo - Brasil Junho de 1984 
11 .

A Deus,

Aos meus Pais,

OFEREÇO

Ao meu esposo e nossos filhos

DEDICO 


\section{A GRADECIMENTOS}

Ao Dr. Clóvis Pompílio de Abreu, Professor do Departa mento de Matemática e Estatística da Escola Superior de Agricultura "Luiz de Queiroz", pela orientação e amizade dedicada.

Ao Dr. Cássio Roberto de Melo Godoi, Professor do De partamento de Matemática e Estatística da ESALQ; pela ajuda e revisão inestimáveis e pela versão do Resumo.

Ao Dr. Humberto de Campos, Coordenador do Curso de Pós-Graduação em Estatística e Experimentação Agronômica, pelo apoio, atenção e ensinamentos durante o curso.

Aos Drs. Décio Barbin e Antonio Francisco Iemma, Professores do Departamento de Matemâtica e Estatística da ESALQ, pela amizade e estima.

Ao Corpo Docente do Departamento de Matemática e Esta tística da ESALQ, pelos conhecimentos transmitidos.

Aos colegas do Curso de Pós-Graduação, pelo apoio, amizade e colaboração prestada.

A todos que de alguma forma colaboraram para a realização do Curso e deste trabalho. 
1. INTRODUCATO $\ldots \ldots \ldots \ldots \ldots \ldots \ldots \ldots \ldots \ldots \ldots \ldots$

2. REVISAO DE LITERATURA ........... 04

3. DELINEAMENTOS DE SEGUNDA ORDEM .......

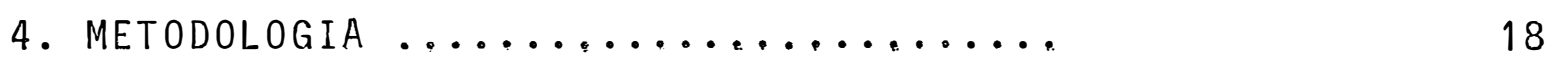

4.1. Ortogonalização dos Delineamentos:

Composto Central e Duplo Composto Central .................... 18

4.1.1. Modelo de Segunda Ordem ..

4.1.2. Sistema de Equações .. Normais e Estimativa dos Parâa metros ..................

4.1.3. Anālise de Variāncia .....

4.1.4. Variāncias e Covariāncias das Estimativas dos Parāme

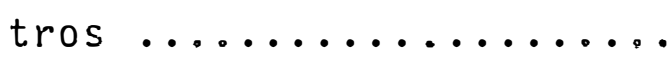

4.2. Comparação entre as Variāncias ..

4.2.1. Eficiência do Delineamento Duplo Composto Central ortogonal em Relação ao Del $\underline{i}$ neamento Composto Central

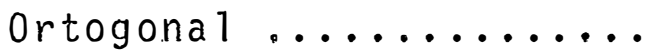

4.2.2. Intervalos de Confiança ..

4.2.3. Variāncias e Intervalos de Confianca das Estimativas das Producões Estimadas ..

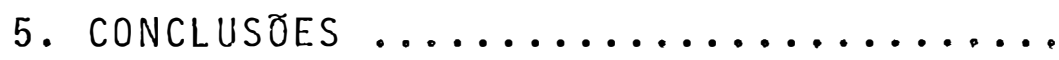


7. APẼNDICE: EXEMPLO DE APLICAÇ̄̄O

7.1. Exemplo Aplicado ao Delineamento

- de 15 pontos .................

7.2. Exemplo Aplicado ao Delineamento de 29 Pontos ............... 
EFICIENCIA DO DELINEAMENTO COMPOSTO CENTRAL ORTOGONAL COM 15 PONTOS EM RELAÇÃO AO DELINEAMENTO DUPLO COMPOSTO CENTRAL ORTOGONAL COM 29 PONTOS

Autora: Ada Castellari

Orientador: Dr. Clóvis Pompilito de Abreu

RESUMO

As pesquisas com fertilizantes tēm sido largamente efetuadas visando ao aumento da produção por unidade de área cultivada. Tais pesquisas revelaram a importância do uso de delineamentos que pos suem um número razoável de níveis e que possibilitem uma anālise econô mica fácil e de simples manejo.

Nos anos 50, BOX e WILSON (1.951) criaram os delineamentos compostos centrais, utilizados inicialmente em pesquisas químicas e posteriormente utilizados em ensaios agrícolas è também estendidos a outros campos de pesquisa.

No presente trabalho foi comparada a eficiência do delineamento Composto Central Ortogonal, para três fatores em 5 níveis equidistantes que vão de zero a quatro, num total de 15 pon tos experimentais sendo um ponto central, oito fatoriais e seis axiais e do delineamento Duplo Composto Central Ortogonal que é uma ex 
tensão do primeiro, em 9 níveis equidistantes que vão de zero a oito, num total de 29 pontos experimentais sendo um ponto central, dezesseis fatoriais e doze axiais.

$\mathrm{Na}$ anālise usou-se o modelo quadrático representado por:

$$
Y_{u}=\beta+\sum_{i=1}^{3} \beta_{i} X_{i u}+\sum_{i=1}^{3} \beta_{i} X_{i u}^{2}+\sum_{\substack{i, j=1 \\ i \neq j}}^{3} \beta_{i j} X_{i u} X_{j u}+e_{u}
$$

onde $u=1,2, \ldots, n$ e $e_{u} \cap N\left(0, \sigma^{2}\right)$.

Durante o estudo foram obtidas as estimativas dos pa râmetros da equação de regressão e seus respectivos intervalos de con fiança e as variâncias dos parâmetros estimados foram comparadas entre os dois delineamentos concluindo-se que:

a. As variâncias das estimativas dos coeficientes do delineamen to Duplo Composto Central Ortogonal foram menores quando comparadas com as do Composto Central Ortogonal (segundo critério de MYERS) (1.971).

b. O uso do delineamento Duplo Composto Central Ortogonal é mais recomendável do que o Composto Central Ortogonal pois além de possibilitar o estudo de três fatores com maior número de níveis, os : coefí cientes quadrāticos têm variância menor quando comparadas àqueles.

c. A eficiência $E$ entre a variância dos parâmetros estimados b's do delineamento Duplo Composto Central Ortogonal e dos a's do Composto Central Ortogonal, para efeitos lineares e interações é igual a 1 e para efeitós quadrāticos, igual a 2,38. 
viii.

THE EFFICIENCY OF THE ORTHOGONAL CENTRAL COMPOSITE WITH 15 POINTS WITH RESPECT TO THE DOBLE ORTHOGONAL CENTRAL COMPOSITE DESIGNS WITH 29 POINTS

Author: Ada Castellari

Adviser: Dr. Clōvis Pompîlio de Abreu

SUMMARY

The fertilizers researchs have been largely done in view of the yield increase by unit area. Such researches showed the im portance of the use of designs having several factor levels making pos sible an easy economic analysis.

In the fifties, BOX and WILSON (1951) created the central composite designs, used inicially in chemical research and furtherly used in agricultural experiments and other fields of application.

In the present work the efficiency of the central com posite for a three 5 level factors in 15 points and the doble orthogonal central composite in 9 levels and 29 points are compared.

During the study the regression parameters are estimated and the corresponding confidence intervals are calculated, con cluding that: 
a, The coefficient estimates have smallest variance in the doble orthogonal central composite case (under .MYERS criteria, 1971).

b. The use of the doble orthogonal central composite design is better than the simple, one as in addition to the study of more factor levêls, the coefficient estimates have smallest variances. c. The efficiencies $\mathrm{E}$ between the variances are 1 for the linear and interaction terms and 2,38 for the quadratic effects. 
1. INTRODUÇÃO

Em programas de pesquisa com fertilizantes, tem-se criado e desenvolvido delineamentos que, empregados em programas de adu bação no estudo de macronutrientes, visam ao estudo das doses ótimas de fertilizantes que possibilitem a maximização do lucro a ser obtido. Isto porque os fertilizantes constituem insumos, tais como custo de produ ção e custo dos próprios fertilizantes, que encarecem, cada vez mais,os custos operacionais da produção agrícola.

No campo agronômico, principalmente em ensaios de adubação, é de interesse do pesquisador expressar os dados da produção da cultura em função da quantidade de nutrientes adicionada ao solo. A fun ção de produção pode ser representada'simbolicamente por:

$$
Y=f\left(x_{1}, x_{2}, \ldots, x_{p}\right)
$$

onde: $\quad$ Y è a produtividade chamada função de resposta;

$$
\begin{gathered}
\mathrm{x}_{1}, \mathrm{x}_{2}, \ldots, \mathrm{x}_{\mathrm{p}} \text { são as quantidades usadas dos nutrientes, de } \\
\text { nominadas variáveis independentes. }
\end{gathered}
$$


Os dados são geralmente provenientes de $\mathrm{N}$ valores de $\mathrm{Y}$, correspondentes a $\mathrm{N}$ combinações dos níveis das doses de nutrientes.

Embora a forma matemática da função de resposta $Y$ se ja desconhecida, pode-se estudā-la em uma região específica, correspondente às combinações de interesse dos níveis das $p$ doses ajustando as variáveis $\mathrm{x}_{1}, \mathrm{x}_{2}, \ldots, \mathrm{x}_{\mathrm{p}}$, na qual todos os termos, até uma determinada ordem, são incluídos de modo que permitam efetuar a análise econômica, ou seja,determinar os níveis de nutrientes que conduzam a uma res posta ōtima.

BOX e WILSON (1951) criaram novos delineamentos para $\underline{\text { a }}$ justar superfícies de resposta de segunda ordem para uso em pesquisas químicas e, posteriormente, utilizados nos esquemas fatoriais $3^{k}$ dos ensaios agrícolas. Sua representação polinomial é:

$$
\begin{aligned}
\widehat{Y}=\hat{a}_{0} & +\hat{a}_{1} X_{1}+\hat{a}_{2} X_{2}+\widehat{a}_{3} X_{3}+\hat{a}_{11} X_{1}^{2}+\hat{a}_{22} X_{2}^{2}+\hat{a}_{33} X_{3}^{2}+\hat{a}_{12} X_{12} X_{2}+ \\
& +\widehat{a}_{13} X_{1} X_{3}+\hat{a}_{23} X_{2} X_{3}
\end{aligned}
$$

Nas pesquisas com adubação, utilizou-se o delineamen to $3^{3}$ principalmente nas culturas com a beterraba açucareira, arroz, trigo, milho, algodão, cana-de-açūcar, feijão e amendoim, com bons resultados. Devido ao aparecimento frequente de "pontos de sela" na anāli se dos experimentos individuais, e mesmo de grupos de experimentos, a1 guns pesquisadores optaram por outros delineamentos, principalmente os do tipo BOX, ou seja, o delineamento composto central. Este delineamen 
to, muito usado na experimentação industrial, pode conter $2^{3}+2(3)+n$ pontos, onde têm-se os níveis codificados $(-1)$ e $(+1)$ para três fatores, dois pontos axiais nas distâncias $(-\alpha)$ e $(+\alpha)$ para cada fator e um ponto central 000 que pode ser repetido $\mathrm{n}_{1}$ vezes para possibilitar a avaliação do erro experimental e a adequação do modelo.

Com o $\underline{\alpha}$ convenientemente escolhido, pode-se obter $o$ delineamento Composto Central Ortogonal, que facilita a obtenção das es timativas dos coeficientes lineares, quadráticos e interações, segundo MYERS (1971).

CONAGIN et alii. (1969) propuseram uma extensão do deli neamento composto central que chamaram de delineamento: Duplo Composto Central visando obter melhor estimativa da curvatura da função de resposta.

No presente trabalho, estudar-se-ä o delineamento Composto Central representado por $2^{3}+2$ (3) $+1=15$ combinações de trata mentos e o delinéamento Duplo Composto Central representado por $2^{3}+2^{3}+2(3)+2(3)+1=29$ combinações de tratamentos.

Serão determinadas as estimativas dos parâmetros da equação de regressão e seus respectivos intervalos de confiança. Serão tambēm, obtidas as variâncias das estimativas dos parâmetros e comparadas entre os dois delineamentos. Além disso, serão determinadas as variâncias e intervalos de confiança das estimativas das produções estima das. 


\section{REVISÃO DE LITERATURA}

A metodologia de superfície de resposta teve grande dị fusão e desenvolvimento a partir de BOX e WIJsON (1951), quando os auto res discutiram delineamentos, com o objetivo de determinar o ponto de resposta máxima, usando o menor número de observações possíveis. Compararam alguns delineamentos experimentais e introduziram, pela primeira vez, o conceito de delineamentos compostos, os quais foram inicialmente utilizados na indústria, onde o erro experimental é geralmente menor. A tualmente são utilizados na agricultura, pois permitem o estudo de diversos niveis de nutrientes, com o uso de um nümero relativamente peque no de parcelas.

CAMPOS (1967) apresentou um trabalho aplicando a regressão polinomial ajustada a dados de ensaios fatoriais $3^{3}$ de adubação NPK, em milho, usando o modelo polinomial: 


$$
\begin{aligned}
\mathrm{Y}= & \mathrm{a}_{0}+\mathrm{a}_{11} \mathrm{X}_{1}^{2}+\mathrm{a}_{22} \mathrm{X}_{2}^{2}+\mathrm{a}_{33} \mathrm{X}_{3}^{2}+\mathrm{a}_{12} \mathrm{X}_{12} \mathrm{X}_{2}+\mathrm{a}_{13} \mathrm{X}_{1} \mathrm{X}_{3}+\mathrm{a}_{23} \mathrm{X}_{2} \mathrm{X}_{3}+ \\
& +\mathrm{a}_{14} \mathrm{X}_{1}+\mathrm{a}_{24} \mathrm{X}_{2}+\mathrm{a}_{34} \mathrm{X}_{3}+\xi
\end{aligned}
$$

Em seu estudo o autor determinou as estimativas dos parâmetros da equação e seus respectivos intervalos de confiança, os níveis ótimos de $\mathrm{N}, \mathrm{P}$ e $\mathrm{K}$, as estimativas e os intervalos de confiança das produções e estudou a natureza do ponto crítico para verificar se era de mäximo, mínimo ou ponto de sela.

O autor fez a seguir um estudo de cortes da superfí cie, fixando dois nutrientes, nas suas doses padrão, obtendo, em cada um dos cortes, a fórmula para cälculo da dose ótima, assim como as variâncias e intervalos de confiança, numa forma aproximada dessas doses. Durante o estudo dos delineamentos: rotativo de BOX e o fatorial $3^{3}$, chegou à conclusão de que o segundo é tão preciso quanto o primeiro.

Após o estudo teórico, o autor fez uma aplicação prätica, concluindo, entre outras, que a aplicação da regressão polinomial aos ensaios fatoriais $3^{3}$. de adubação é recomendada apenas a grupos de ensaios e de boa precisão.

VIEIRA (1970) estudou quatro funções de produção aplí cadas aos ensaios fatoriais $3^{3}$ de NPK em milho, sendo três modelos de superficie de resposta: $\mathrm{X}^{2}, \sqrt{\mathrm{X}}$ e $\mathrm{X}^{3 / 2}$ e um modelo de re gressão assintótica (Lei de Mitscherlich). Dentre outras, conclui a au 
tora que o modelo raíz quadrada apresentou os mais altos valores dos coeficientes de determinação $\mathrm{R}^{2}$ enquanto que o modelo quadrático e o de grau $3 / 2$ revelaram-se praticamente iguais nos resultados.

Recomenda a autora que, para a determinação da dose econômica de nutrientes no caso de 3 níveis, o uso da Lei de Mitscherlich, porque leva a soluções satisfatōrias através de métodos matemátí cos simples. Entretanto, se existirem interações significativas de nutrientes ou se houver queda de produção devida a doses altas, recomenda-se a aplicação da regressão polinomial, preferencialmente o modelo de raíz quadrada.

PIMENTEL GOMES e CAMPOS (1972) discutiram a precisão das estimativas entre os delineamentos: fatorial $3^{3}$ e o central rotati vo de BOX com 15 tratamentos, concluindo que o primeiro é mais eficien te do que o segundo por apresentar variância menor nas estimativas dos parâmetros. Concluíram, também que, com relação a eñsaios com fertilizantes, o melhor è ter-se o mesmo intervalo de confiança na adubação das doses para cada parâmetro em ambos os delineamentos.

OLIVEIRA (1974) realizou um estudo teórico comparando a precisão das estimativas dos coeficientes dos modelos do grupo fatorial $3^{\mathrm{K}}$ para $\mathrm{K}=2,3,4$, relativamente às estimativas correspondentes nos modelos do delineamento Composto Central Rotativo para $\mathrm{K}=2,3,4$, usando-se um ou mais pontos no centro.

Para cada delineamento foram obtidas as respectivas matrizes de dispersão, cujos termos comparados, após conveniente equi- 
valência de escala, levou à conclusão de que o fatorial $3^{\mathrm{K}}$ mostrou - se mais eficiente, pois forneceu variâncias das estimativas dos coeficientes muito menores.

costa (1977) fez um estudo comparativo de 3 modelos de regressão polinomial aplicados a 27 ensaios fatoriais de adubação NPK em cultura de arroz, no Estado de Goiās. Os modelos foram $\mathrm{X}^{2}$, raíz quadrada de $\mathrm{x}^{2} \mathrm{e}^{3 / 2}$. Verificou o autor que os resultados obtidos pelos mo delos quadrático e de grau $3 / 3$ praticamente não diferiam entre si, levando-o, assim, a abandonar o estudo com o de grau $3 / 2$ por ser de maior complexidade e apresentar cálculos mais laboriosos.

Dentre outras, o autor concluiu que os valores de $F$ das regressões e os coeficientes de determinação $\mathrm{R}^{2}$ em ambos os modelos foram concordantes em todos os casos estudados. Ambos os modelos apresentaram, em alguns casos, doses económicas fora do intervalo estudado. As doses econômicas obtidas nos cortes foram bastante próximas das encontradas nas superficies, sendo seus intervalos de confiança muito amplios, dificultando a recomendação de adubação. Recomenda o autor a apli cação das superficies de resposta somente para grupos de ensaios e de boa precisão.

MONTEIRO (1978) aplicou os modelos de regressão polino mial e de regressão assintótica (Lei de Mitscherlich) aos dados de produção provenientes de ensaios fatorial $3^{3}$ de adubação NPK em amendoim, concluindo que os dois modelos apresentaram um bom ajuste aos dados experimentais e que os intervalos de confiança para os rendimentos atravès do modelo polinomial quadrático foram estreitos. 
Recomenda o autor, ambos os modelos, na determinação das doses econômicas de nutrientes para o caso de três níveis, para gru pos de ensaios de boa precisão, sendo que pela Lei de Mitscherlich chega-se a resultados razoāveis, através de cālculos imediatos.

CONAGIN e JORGE (1979) apresentaram um trabalho sobre - Delineamento Duplo Composto Central, desenvolvido para o estudo de três fatores e mais de três niveis.

No trabalho são apresentados o delineamento não ortogo nal completamente casualizado, estudado com três fatores em cinco níveis, o ortogonal completamente casualizado com três fatores em nove ní veis, e o ortogonal divisível em dois blocos com três fatores em nove niveis.

Os autores concluíram que os três delineamentos, quando comparados com o delineamento fatorial $3^{3}$, revelaram propriedades a]. tamente vantajosas, pois possibilitam a estimação mais eficiente dos coeficientes quadrāticos, responsáveis pela curvatura da função e, consequlentemente, pela localização do ponto ótimo econömico.

Concluíram, também, que esses delineamentos são sụperiores ao $3^{3}$ por possibilitarem o estudo de três fatores com maior núme ro de níveis, e por estimarem os coeficientes quadrāticos com variāncia menor que as do $3^{3}$.

JORGE (1980) fez a anālise do delineamento Guadalupe para três fatores, usando o modelo polinomial quadrätico, com polinômios ortogonais do primeiro e segundo graus. 
Entre outras, a autora concluiu, segundo critério de PIMENTEL GOMES E CAMPOS (1967) que

(a) para ensaios de adubação, o delineamento Guadalupe original é menos eficiente que o fatorial $3^{3}$ e maịs eficiente que o composto central original;

(b) em ensaios de adubação, o delineamento Guadalupe ortogonal é menos eficiente que o Guadalupe original e que o fatorial $3^{3}$; em relação ao central composto original, o Guadalupe ortogonal è mais eficiente na estimativa dos componentes quadräti$\cos$

LIMA (1980) aplicando os modelos de regressão polinomial e de regressão assintótica (Lei de Mitscherlich), em produções pro venientes de ensaios fatoriais $3^{3}$ incompletos de adubação MPK em mandio ca, no Estado do Cearä, concluiu que para ambos os modelos os intervalos de confiança para os parâmetros foram bastante amplos e os intervar los de confiança para os rendimentos foram estreitos.

NICOLELLA (1981), utilizando dados de 5 ensaios instar lados em blocos casualizados com duas repetições e quinze tratamentos, em cultura de cacau, no Estado da Bahia, estudou o comportamento do modelo polinomial quadrático (com e sem interação).

0 autor dèterminou as estimativas dos parâmetros de equação de regressão e as estimativas dos rendimentos, bem como seus res pectivos intervalos de confiança, concluindo que os parâmetros da equar 
ção apresentaram intervalos de confiança amplos, resultando em uma imprecisão nas estimativas dos rendimentos.

Concluiu, também, que o uso da superfície de resposta na interpretação de ensaios de adubação NPK, utilizando-se para o ajuste dos dados de produção a função polinomial quadrática, revelou-se ina dequado, na cultura de cacau no Estado da Bahia.

CONAGIN (1982-A) realizou um trabalho sobre delineamentos Duplos Compostos Centrais constituídos de. dois fatoriais nos niveis $\pm_{1}$ e $\stackrel{+}{w}_{w}$, pontos axiais nos niveis $\pm_{\alpha}$ e $\pm_{-\gamma \alpha}$, para cada fator e pontos centrais e que pode apresentar cinco, sete ou nove níveis para cada fator.

0 trabalho apresenta três tipos de delineamentos:

os delineamentos que além de ortogonais são subdivisíveis em dois, três ou cinco blocos, cujos níveis $w$, da parte fatorial, são menores que dois, condição esta que os torna bastante desejáveis na prática pois ní veis mais altos são raramente utilizados; (2) os delineamentos ortogonais, divisiveis ortogonalmente em blocos com os pontos da parte fato-

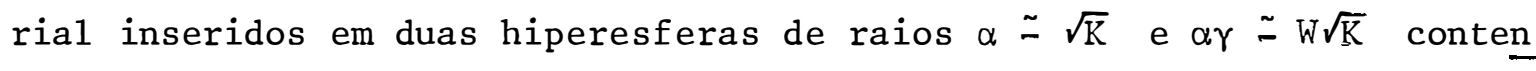
do dois ou quatro pontos centrais; (3) os delineamentos ortogonais, rom tacionais ou quase completamente rotacionais, sendo, também, divisíveis ortogonalmente, em dois, três ou cinco blocos, visando fornecer uma boa estimação do erro experimental e um teste mais preciso de adequação ao mode1o. 
Conclui que esses delineamentos podem ser de utilidade na pesquisa agrícola e na pesquisa com fertilizantes, em que a subdivisão em blocos é muito importante, possibilitando uma determinação preci sa da dose econômica dos fertilizantes, e também nos casos em que é importante cobrir a área pesquisada com várias doses de cada fator. CONAGIN (1982-B) apresentou um trabalho sobre delineamentos Compostos Centrais Ortogonais, Rotacionais e Divisíveis em Blocos, cujos delineamentos possuem a propriedade dos delineamentos Com postos Centrais Ortogonais onde a estimação dos coeficientes do modelo è facilmente obtida, e possuem também a propriedade dos Compostos Centrais Ortogonais Rotacionais que apresentam uma uniformidade de variâncias para os pontos que se encontram a mesma distância do centro de de1ineamento.

Concluiu que os delineamentos que possuem essas três propriedades possibilitam uma estimativa precisa do erro e que o teste de adequação do modelo pode ser feito, e com precisão razoável.

Aconselha, para o caso de experimentos de adubação,que deve-se.calibrar bem a amplitude das doses escolhidas, de forma que as decisões econômicas ôtimas possam estar situadas no intervalo de zero a uma das doses, mais próximas de zero do que de um. 
12.

\section{DELINEAMENTOS DE SEGUNDA ORDEM}

0 modelo de regressão polinomial de segundo grau, com três variáveis independentes $x_{1}, x_{2}$ e $x_{3}$, é dado pela seguinte equação:

$$
\begin{aligned}
y_{j}=a_{0} & +a_{1} x_{1}+a_{2} x_{2}+a_{3} x_{3}+a_{11} x_{1}^{2}+a_{22} x_{2}^{2}+a_{33} x_{3}^{2}+ \\
& +a_{12} x_{1} x_{2}+a_{13} x_{1} x_{3}+a_{23} x_{2} x_{3}+e_{j}
\end{aligned}
$$

onde $e_{j} \cap N\left(0, \sigma^{2}\right)$.

BOX e WILSON (1951) introduziram os delineamentos com postos para ajustar superfícies de resposta de segunda ordem. Esses de lineamentos são construidos pela adição de combinações de tratamentos àquelas que são obtidas de um fatorial $2^{\mathrm{k}}$. Se os níveis codificados de cada variável $x$ são $(-1)$ e $(+1)$ no fatorial $2^{k}$, adicionando-se a estes as $(2 \mathrm{k}+\mathrm{p})$ combinações obtemos os Delineamentos Compostos Centrais. 
Dessa forma, tem-se que o delineamento Composto Central subdivide-se em três partes:
(a) $2^{\mathrm{k}}$ : pontos do fatorial
(b) $2 \mathrm{k}$ : pontos axiais, isto é, pontos localizados sobre o eixo
à uma distância $\alpha$ do centro.
(c) $\mathrm{p}$ : pontos centrais.

Assim, o nümero total de combinações de tratamentos, ou seja, o nümero total de pontos é dado por $\left(2^{k}+2 k+p\right)$. Usando-se um ponto no centro tem-se $\left(2^{k}+2 k+1\right)$ como o nümero total de combinações de tratamentos. Assim, para 2, 3 e 4 fatores, o experimento requer 9, 15 e 25 unidades, respectivamente, comparados com 9,27 e 81 no grupo $3^{k}$.

Estudar-se-ā o delineamento Composto Central com $\mathrm{k}=3$ e $\mathrm{p}=1$ ponto central, representado por $2^{3}+2(3)+1=15$ nümero to ta1 de tratamentos onde:

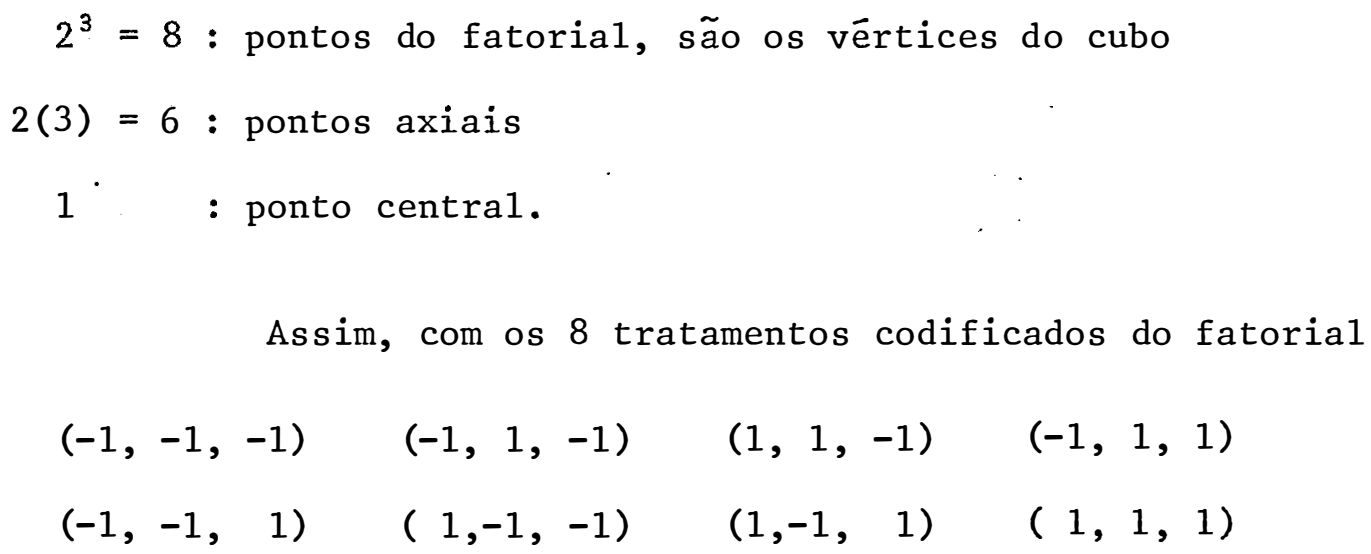

adicionados aos 6 pontos axiais: 


$$
\begin{array}{lll}
(-\alpha, 0,0) & (\alpha, 0,0) \\
(0,-\alpha, 0) & (0, \alpha, 0) \\
(0,0,-\alpha) \quad, & (0,0, \alpha)
\end{array}
$$

mais 1 ponto central: $(0,0,0)$, obtêm-se os 15 tratamentos, cuja representação gráfica è dada por:

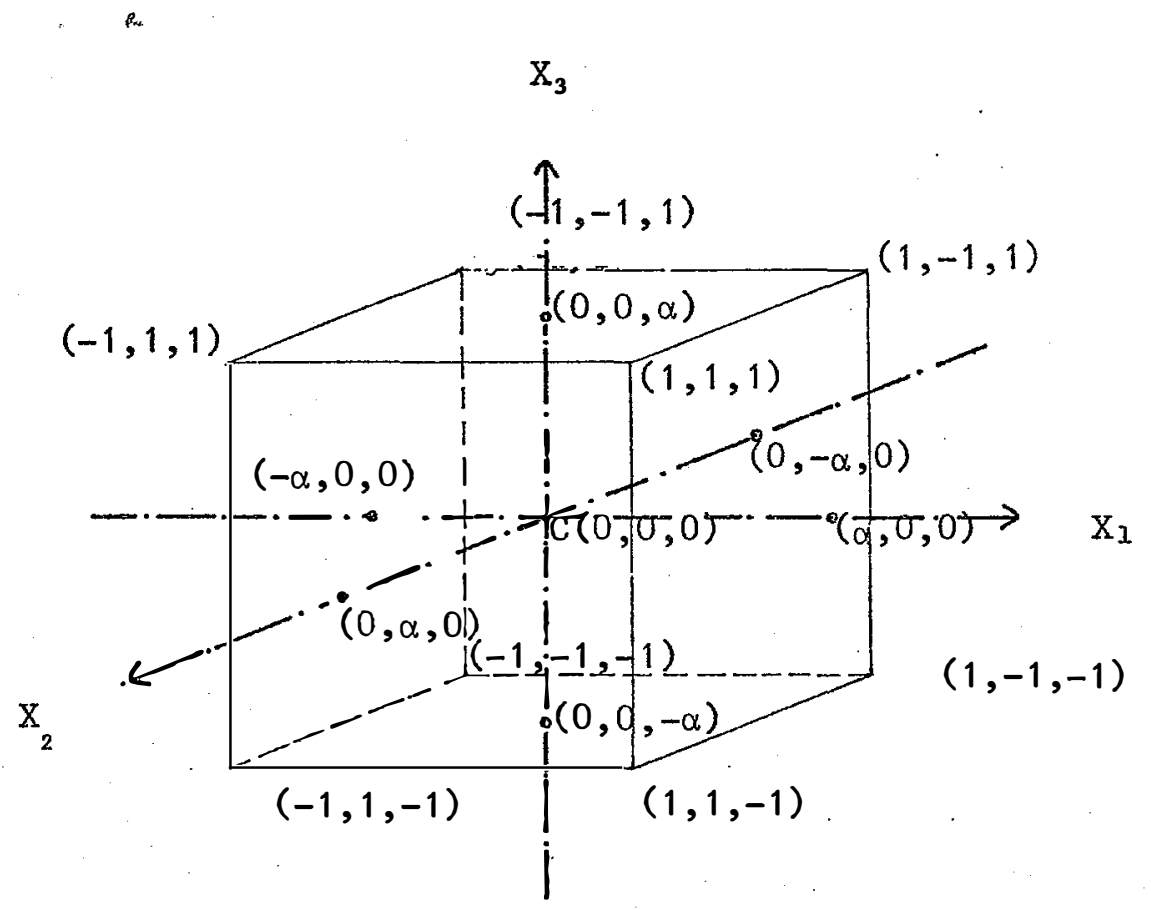

FIGURA 1 - Delineamento Composto Central no nive1 $\alpha$.

CONAGIN et alii (1968) introduziram o delineamento Du plo Composto Central visando uma estimativa mais eficiente dos coeficientes quadráticos, obtendo, assim, melhor estimativa da curvatura da função de resposta responsāvel pela localização do ponto ótimo econômico. 
Este delineamento é composto de 29 pontos distribuídos em dois cubos situados nas distâncias $\alpha$ e $2 \alpha$, e um ponto central, cu ja representação pode ser dada por: $2^{3}+2^{3}+2(3)+2(3)+1=29$ com binações de tratamentos.

Assim com os $2^{3}+2^{3}=16$ tratamentos codificados do fatoria1:

$$
\begin{array}{lllll}
(-2,-2,-2) & (-2,2,2) & (-1,-1,-1) & (-1,1,1) . \\
(-2,-2,2) & (2,-2,2) & (-1,-1,1) & (1,-1,1) \\
(-2,2,-2) & (2,2,-2) & (-1,1,-1) & (1,1,-1) \\
(2,-2,-2) & (2,2,2) & (1,-1,-1) & (1,1,1)
\end{array}
$$

somados com os $2(3)+2(3)=12$ pontos axiais

$$
\begin{array}{llllll}
(-2 \alpha, 0,0) & (2 \alpha, 0,0) & (-\alpha, 0,0) & (\alpha, 0,0) \\
(0,-2 \alpha, 0) & (0,2 \alpha, 0) & (0,-\alpha, 0) & (0, \alpha, 0) \\
(0,0,-2 \alpha) & (0,0,2 \alpha) & (0,0,-\alpha) & (0,0, \alpha)
\end{array}
$$

mais 1 ponto central $(0,0,0)$, têm-se os 29 tratamentos, que graficamente são assim representados: 


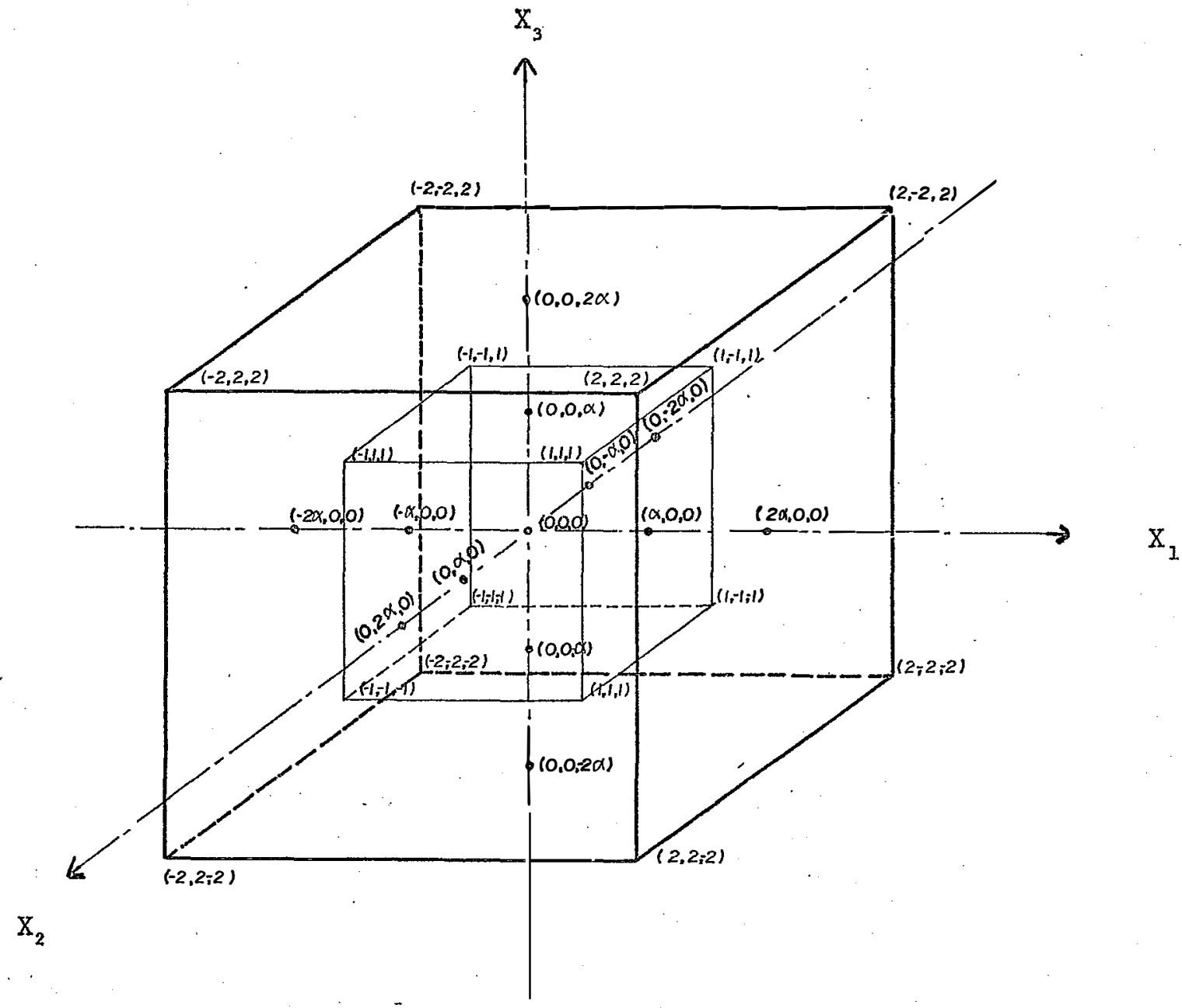

FIGURA 2 - Delineamento Duplo Composto Centra1 nos níveis $\alpha$ e $2 \alpha$.

0 valor $\alpha$ pode ser escolhido para tornar os coeficientes de regressão ortogonais o que facilita a estimação dos parâmetros e a anālise de variância correspondente (BOX e WILSON, 1951); ou para minimizar o desvio que resulta se a forma verdadeira da superfície 
de resposta não for quadrática, ou para dar ao delineamento a proprieda de de ser rotacional, o que se caracteriza por ter a variância da resposta estimada constante em pontos equidistantes do centro (BOX e HUNTER, 1957). 
18.

4. METODOLOGIA

4.1. Ortogonalização dos Delineamentos: Composto Central e Duplo Composto Central.

A metodologia usada para a ortogonalização dos delinea mentos baseia-se dentre outros, nos trabalhos de BOX e WILSON (1951) e CONAGIN E JORGE (1979).

Para cada delineamento é obtida a matriz de disper são e, pela comparação dos termos das matrizes, após conseguir-se conve niente equivalência de escala, poder-se-à avaliar a eficiência dos deli neamentos.

Atravēs desta metodologia, serā comparada a preci são das estimativas dos coeficientes do delineamento Composto Central or togonal (C.C.O.) com 15 tratamentos com as estimativas correspondentes, obtidas no delineamento Duplo Composto Central Ortogona1 (D.C.C.O.) com 29 tratamentos. 
4.1.1. Modelo de Segunda Ordem

No presente trabalho será indicado por:

$$
\begin{aligned}
y_{j}=a_{0} & +a_{1} x_{1}+a_{2} x_{2}+a_{3} x_{3}+a_{11} x_{1}^{2}+a_{22} x_{2}^{2}+a_{33} x_{3}^{2}+a_{12} x_{12} x_{2}+ \\
& +a_{13} x_{13} x_{3}+a_{23} x_{2} x_{3}+e_{j}
\end{aligned}
$$

o :modelo de superfície de resposta relativa ao delineamento Composto Centra1 Ortogona1.

Os 15 tratamentos codificados são:

$$
\begin{aligned}
& (-1,-1,-1) \quad(1,1,-1) \quad(1,-1,-1) \quad(-\alpha, 0,0)(\alpha, 0,0) \\
& (-1,1,1) \quad(-1,-1,1) \quad(1,1,1) \quad(0,-\alpha, 0)(0, \alpha, 0) \\
& (1,-1,1) \quad(-1,1,-1)(0,0,0)(0,0,-\alpha)(0,0, \alpha)
\end{aligned}
$$
delineamento Duplo Composto Central Ortogonal será indicado por:

$$
\begin{aligned}
y_{j}=b_{0} & +b_{1} x_{1}+b_{22} x_{2}+b_{33} x_{3}+b_{11} x_{1}^{2}+b_{22} x_{2}^{2}+b_{33} x_{3}^{2}+b_{12} x_{12} x_{2}+ \\
& +b_{13} x_{13} x_{3}+b_{23} x_{23} x_{3}+e_{j}
\end{aligned}
$$

Os 29 tratamentos codificados são: 


$$
\begin{array}{llll}
(-2,-2,-2) & (-2,-2,-2) & (1,-1,1) \\
(-2,2,2) & (2,-2,-2) & (1,1,-1) \\
(2,-2,2) & (2,2,2) & (-1,-1,1) \\
(2,2,-2) & (-1,-1,-1) & (-1,1,-1) \\
(-2,-2,2) & (-1,1,1) & (1,-1,-1) \\
(1,1,1) & (2 \alpha, 0,0) & (0,0,-\alpha) \\
(0,0,0) & (0,2 \alpha, 0) & (\alpha, 0,0) \\
(-2 \alpha, 0,0) & (0,0,2 \alpha) & (0, \alpha, 0) \\
(0,-2 \alpha, 0) & (-\alpha, 0,0) & (0,0, \alpha) \\
(0,0,-2 \alpha) & (0,-\alpha, 0) &
\end{array}
$$

Considerando-se:

Y o vetor das produções;

$\mathrm{X}$ a matriz dos valores assumidos por $\mathrm{X}_{1}, \mathrm{X}_{2}$ e $\mathrm{X}_{3}$ nos trata mentos considerados;

$\beta$ o vetor dos parâmetros;

$\xi$ o vetor dos erros

pode-se escrever os modelos dos delineamentos na forma matricial dada por:

$$
\mathrm{Y}=\mathrm{X} \beta+\xi
$$

Considerando-se ainda que a matriz $x^{\prime}=\left[x_{1}, x_{2}, x_{3}\right]$ é constituida dos valores dos tratamentos codificados e considerando a correção para a média introduzida nos termos quadráticos pela expressão $\sum_{i}\left(x_{i}^{2}-c\right)=0$, têm-se os polinômios: 
para o delineamento composto central ortogonal:

$$
\begin{aligned}
& \hat{\mathrm{Y}}=\hat{\mathrm{a}}_{0}+\hat{\mathrm{a}}_{1} \mathrm{x}_{1}+\hat{\mathrm{a}}_{2} \mathrm{x}_{2}+\hat{\mathrm{a}}_{3} \mathrm{x}_{3}+\hat{\mathrm{a}}_{11}\left(\mathrm{x}_{1}^{2}-\mathrm{c}\right)+\hat{\mathrm{a}}_{22}\left(\mathrm{x}_{2}^{2}-\mathrm{c}\right)+ \\
& +\hat{a}_{33}\left(x_{3}^{2}-c\right)+\hat{a}_{12} x_{1} x_{2}+\hat{a}_{13} x_{13} x_{3}+\hat{a}_{23} x_{2} x_{3} \text {. }
\end{aligned}
$$

e para o delineamento duplo composto central ortogonal:

$$
\begin{aligned}
\hat{\mathrm{Y}}=b_{0} & +b_{1} x_{1}+b_{2} x_{2}+b_{3} x_{3}+b_{11}\left(x_{1}^{2}-c\right)+b_{22}\left(x_{2}^{2}-c\right)+ \\
& +b_{33}\left(x_{3}^{2}-c\right)+b_{12} x_{1} x_{2}+b_{13} x_{1} x_{3}+b_{23} x_{2} x_{3} .
\end{aligned}
$$

o vetor $Y$ das produções $j$ correspondentes aos tratamentos numerados de 1 a 15 , e a matriz $\mathrm{X}$ das variáveis independentes para o delineamento Composto Central Ortogonal, são dados na Ta bela 1, e para o delineamento Duplo Composto Central Ortogonal, com os tratamentos numerados de 1 a 29, na Tabela 2 . 


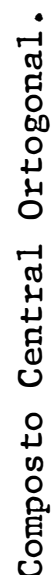

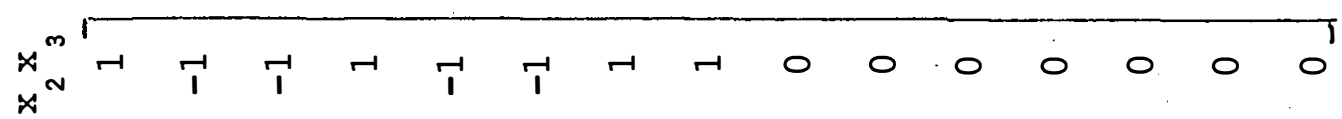

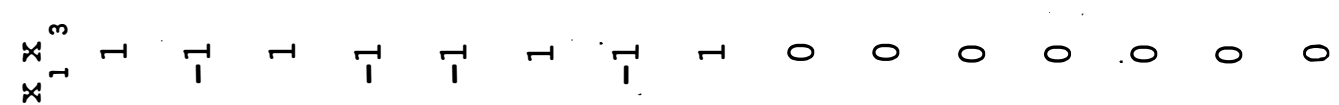
$\begin{array}{llllllllllll}x^{-1} & -1 & -1 & 1 & -1 & 1 & -1 & 0 & 0 & 0 & 0 & 0\end{array}$

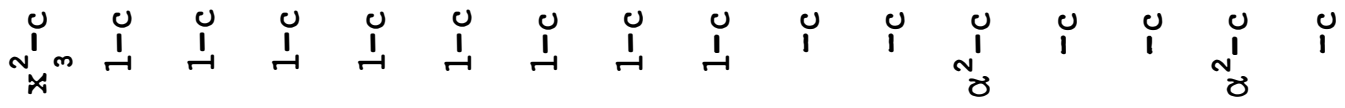

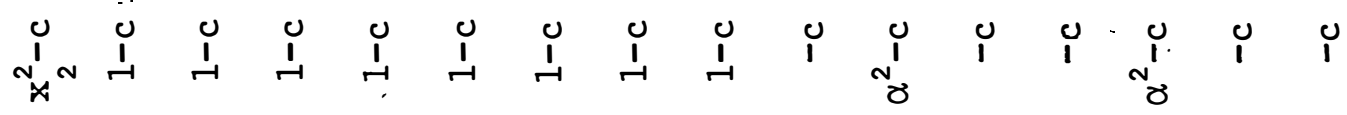

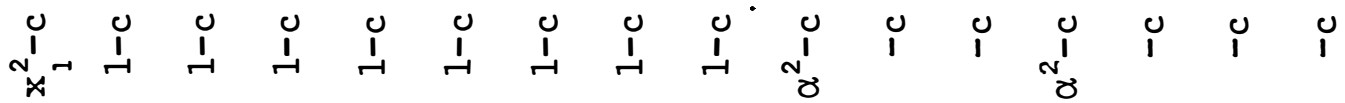

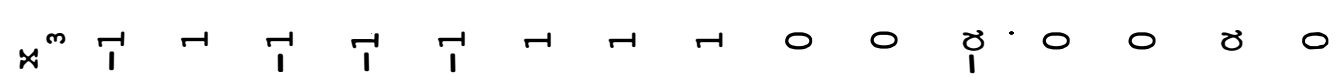

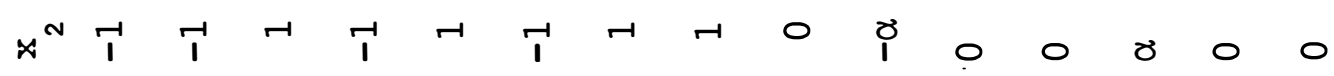

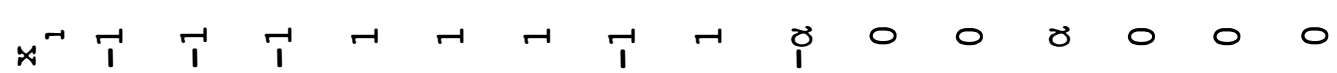

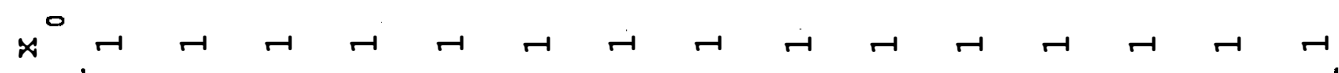
$x^{11}$

0

D

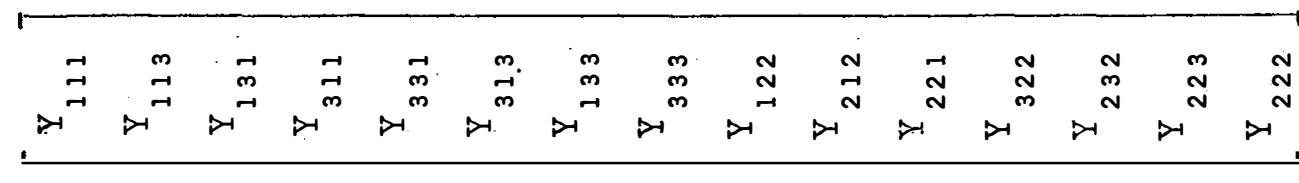

II

$\underset{H}{4}$ 

Central Ortogonal.

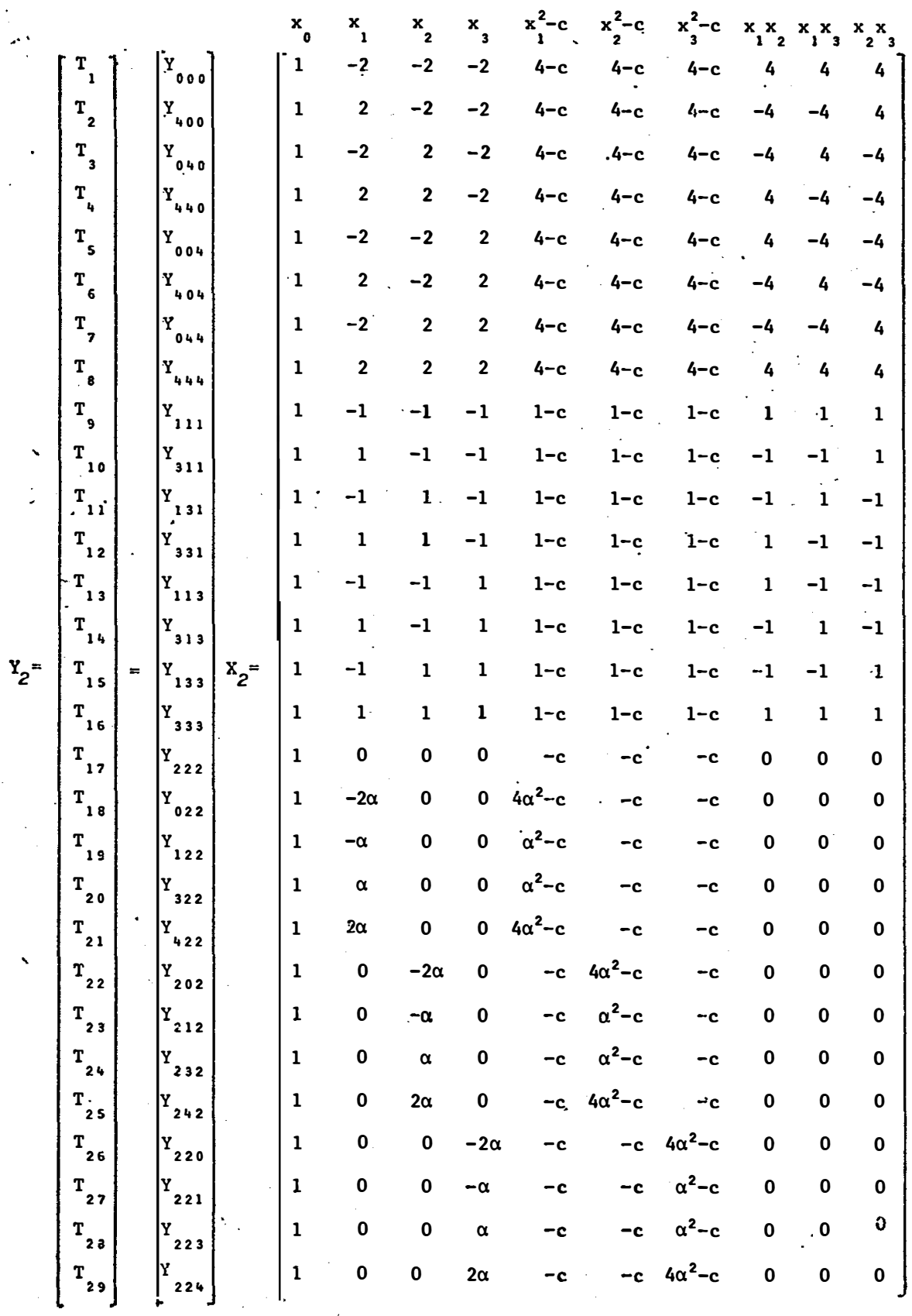


4.1.2. Sistema de Equações Normais e Estimativa dos Parâmetros

$$
\text { Matricialmente tem-se que } \mathrm{Y}=\mathrm{X} \beta+\varepsilon \text { e, pela minimi- }
$$

zação da soma dos quadrados dos desvios $\left(\varepsilon^{\prime} \varepsilon\right)$, tem-se o sistema de equa ções normais dado por:

$$
X^{\prime} X \hat{\beta}=X^{\prime} Y
$$

Seja a matriz $\mathrm{S}_{1}=\mathrm{X}_{1}^{\mathrm{x}} \mathrm{X}_{1}$ para o delineamento Composto Central Ortogonal dada por:

$\mathrm{S}_{1}=\mathrm{X}_{1} \mathrm{X}_{1}=\left[\begin{array}{cccccccccc}15 & 0 & 0 & 0 & 0 & 0 & 0 & 0 & 0 & 0 \\ 0 & 8+2 \alpha^{2} & 0 & 0 & 0 & 0 & 0 & 0 & 0 & 0 \\ 0 & 0 & 8+2 \alpha^{2} & 0 & 0 & 0 & 0 & 0 & 0 & 0 \\ 0 & 0 & 0 & 8+2 \alpha^{2} & 0 & 0 & 0 & 0 & 0 & 0 \\ 0 & 0 & 0 & 0 & \mathrm{M}_{1} & \mathrm{~T}_{1} & \mathrm{~T}_{1} & 0 & 0 & 0 \\ 0 & 0 & 0 & 0 & \mathrm{~T}_{1} & \mathrm{M}_{1} & \mathrm{~T}_{1} & 0 & 0 & 0 \\ 0 & 0 & 0 & 0 & \mathrm{~T}_{1} & \mathrm{~T}_{1} & \mathrm{M}_{1} & 0 & 0 & 0 \\ 0 & 0 & 0 & 0 & 0 & 0 & 0 & 8 & 0 & 0 \\ 0 & 0 & 0 & 0 & 0 & 0 & 0 & 0 & 8 & 0 \\ 0 & 0 & 0 & 0 & 0 & 0 & 0 & 0 & 0 & 8\end{array}\right]$

onde 
onde: $M_{1}=8(1-c)^{2}+2\left(\alpha^{2}-c\right)^{2}+5(c)^{2}$

$$
T_{1}=8(1-c)^{2}-4 c\left(\alpha^{2}-c\right)+3(c)^{2}
$$

Efetuando as operações e simplificando, chega-se a

$$
M_{1}=T_{1}+2 \alpha^{4}
$$

A partir da equação em $\mathrm{T}_{1}$, obtēm-se:

$$
T_{1}=8+15 c^{2}-16 c-4 c \alpha^{2}
$$

Substituindo $c=2\left(4+\alpha^{2}\right) \div 15$, fazendo $\alpha^{2}=z$, e lembrando que para a matriz ficar diagonal, devemos ter $T_{1}=0$, chega-se à equação $z^{2}+8 z-14=0$, cuja raiz vālida é a positiva,

$$
z=\alpha^{2}=1,4772, \text { de onde } \alpha=1,2154 \text {. }
$$

Portanto usando $\alpha=1,2154$ obtém-se o delineamento Composto Centra1 Ortogonal.

Para o delineamento Duplo Composto Central Ortogonal o raciocínio è idêntico. Seja a matriz 
$\mathrm{S}_{2}=\mathrm{X}_{2}^{\prime} \mathrm{X}_{2}=\left[\begin{array}{cccccccccc}29 & 0 & 0 & 0 & 0 & 0 & 0 & 0 & 0 & 0 \\ 0 & 40+10 \alpha^{2} & 0 & 0 & 0 & 0 & 0 & 0 & 0 & 0 \\ 0 & 0 & 40+10 \alpha^{2} & 0 & 0 & 0 & 0 & 0 & 0 & 0 \\ 0 & 0 & 0 & 40+10 \alpha^{2} & 0 & 0 & 0 & 0 & 0 & 0 \\ 0 & 0 & 0 & 0 & \mathrm{M}_{2} & \mathrm{~T}_{2} & \mathrm{~T}_{2} & 0 & 0 & 0 \\ 0 & 0 & 0 & 0 & \mathrm{~T}_{2} & \mathrm{M}_{2} & \mathrm{~T}_{2} & 0 & 0 & 0 \\ 0 & 0 & 0 & 0 & \mathrm{~T}_{2} & \mathrm{~T}_{2} & \mathrm{M}_{2} & 0 & 0 & 0 \\ 0 & 0 & 0 & 0 & 0 & 0 & 0 & 136 & 0 & 0 \\ 0 & 0 & 0 & 0 & 0 & 0 & 0 & 0 & 136 & 0 \\ 0 & 0 & 0 & 0 & 0 & 0 & 0 & 0 & 0 & 136\end{array}\right]$

onde

$$
\begin{aligned}
& M_{2}=8(4-c)^{2}+8(1-c)^{2}+9(c)^{2}+2\left(4 \alpha^{2}-c\right)^{2}+2\left(\alpha^{2}-c\right)^{2} \\
& T_{2}=8(4-c)^{2}+8(1-c)^{2}+5(c)^{2}-4 c\left(4 \alpha^{2}-c\right)-4 c\left(\alpha^{2}-c\right)
\end{aligned}
$$

Efetuando as operações e simplificando tem-se:

$$
\mathrm{M}_{2}=\mathrm{T}_{2}+34 \alpha^{4}
$$

Substituindo em $\mathrm{T}_{2}$ o. valor de c, fazendo $\mathrm{T}_{2}=0 \mathrm{e}$ resolvendo a equação em $z$, chega-se a $z=\alpha^{2}=2,2801$ onde $\alpha=1,5100$.

Substituindo $\alpha$ pelos seus respectivos valores nas ma trizes $\mathrm{S}_{1}$ e $\mathrm{S}_{2}$, agora diagonais, obtēm-se 


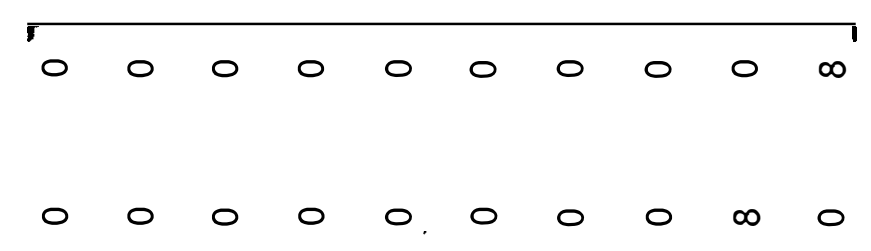

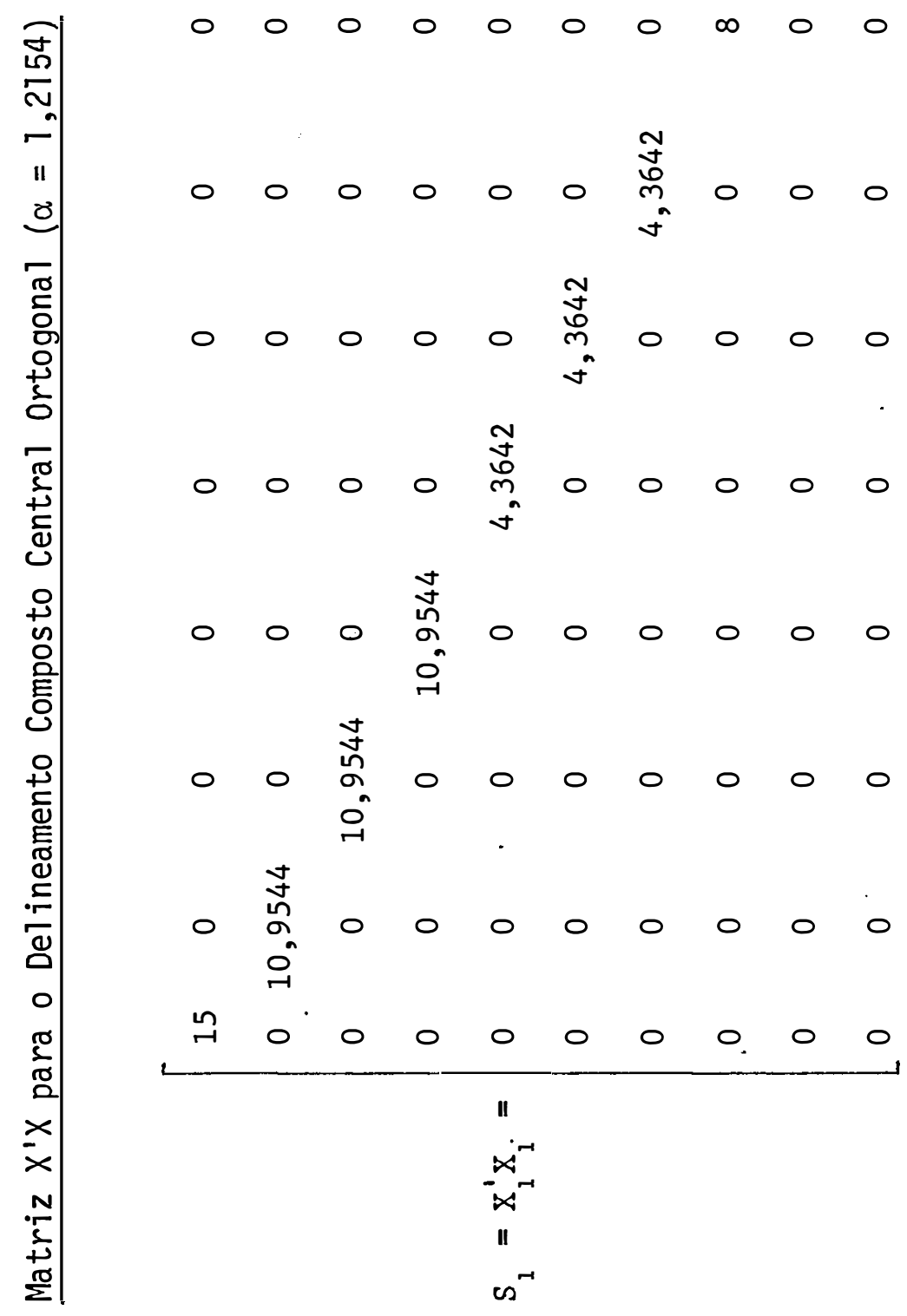


28.

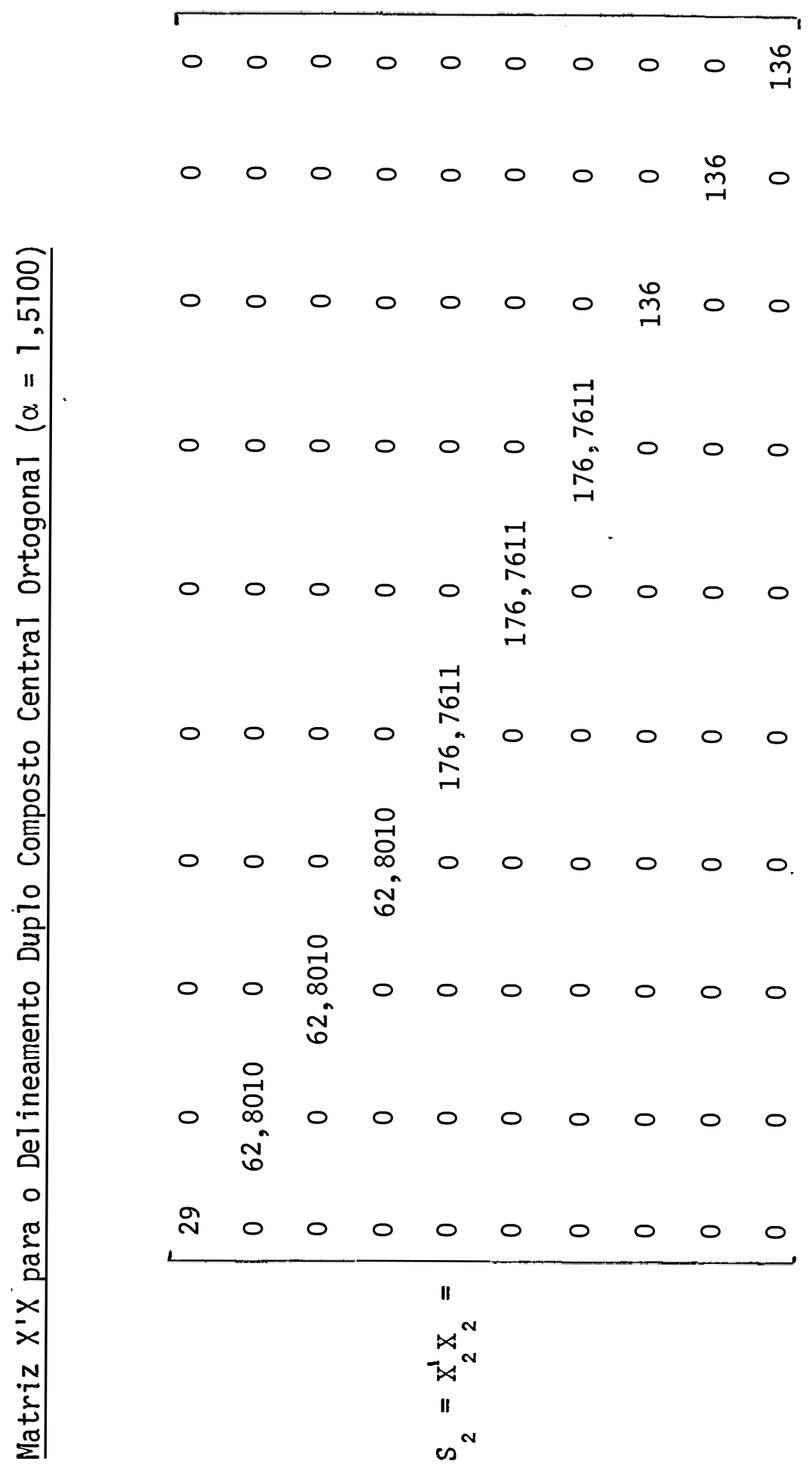


As estimativas dos parâmetros da equação de regressão são obtidas a partir da solução do sistema de equações normais:

$$
\widehat{\beta}=\left(X^{\prime} X\right)^{-1} X^{\prime} Y=S^{-1} X^{\prime} Y
$$

Assim, para o delineamento composto central ortogonal

$$
\mathrm{S}_{1}^{-1}=\left(\mathrm{X}_{1}^{\prime} \mathrm{X}_{1}\right)^{-1}=\operatorname{diag}\left(\begin{array}{l}
\frac{1}{15} ; 0,0913 ; 0,0913,0,0913 ; 0,2291 ; 0,2291 ; \\
0,2291 ; \frac{1}{8} ; \frac{1}{8} ; \frac{1}{8}
\end{array}\right)
$$

e para o delineamento duplo composto central ortogonal

$$
\mathrm{S}_{2}^{-1}=\left(\mathrm{X}_{2}^{\prime} \mathrm{X}_{2}\right)^{-1}=\operatorname{diag}\left(\begin{array}{l}
\frac{1}{29} ; 0,0159 ; 0,0159 ; 0,0159 ; 0,005657 ; \\
0,005657 ; 0,005657 ; \frac{1}{136} ; \frac{1}{136} ; \frac{1}{136}
\end{array}\right)
$$

As matrizes $\mathrm{X}$ e $\mathrm{X}^{\prime} \mathrm{Y}$, para ambos os delineamentos, são dadas a seguir: 


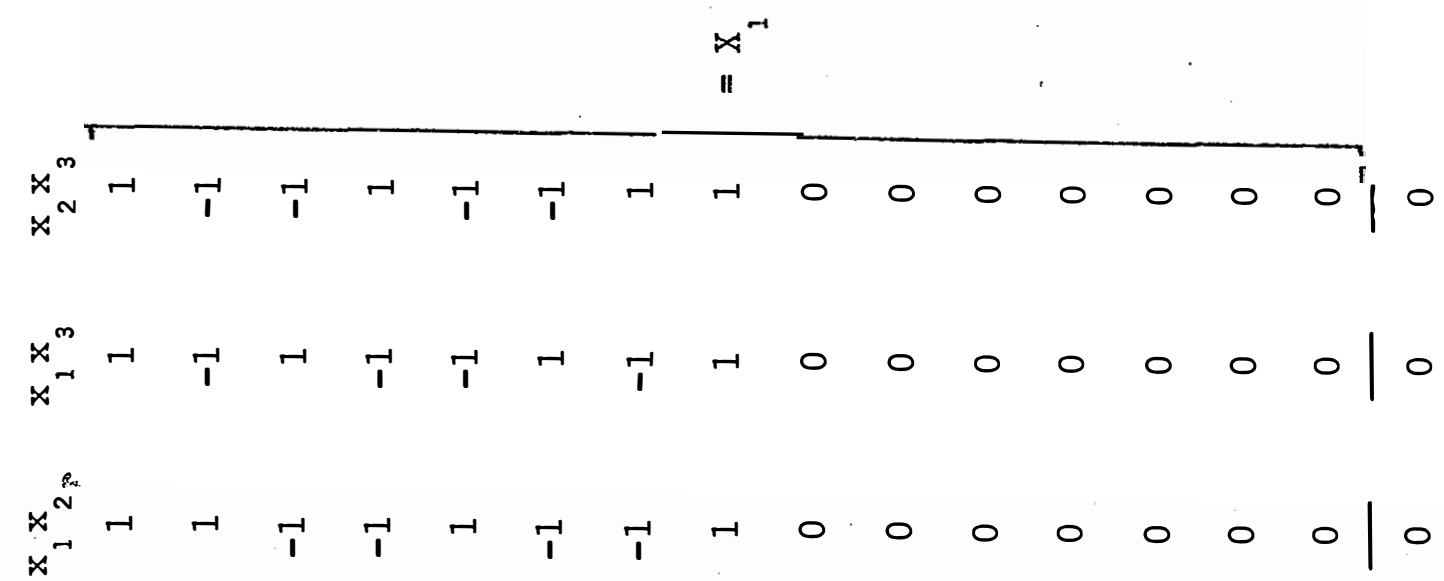

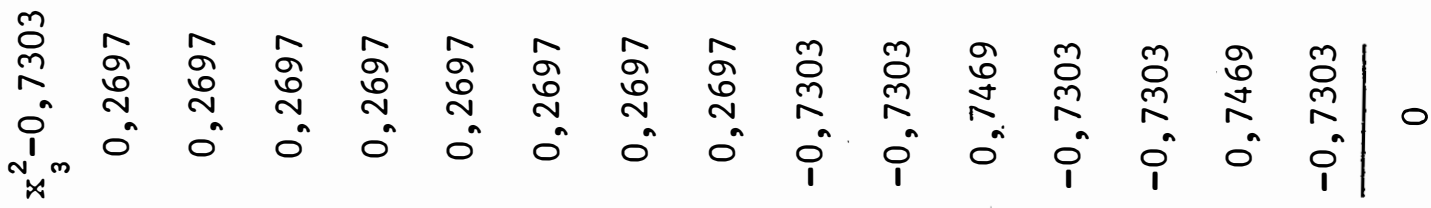

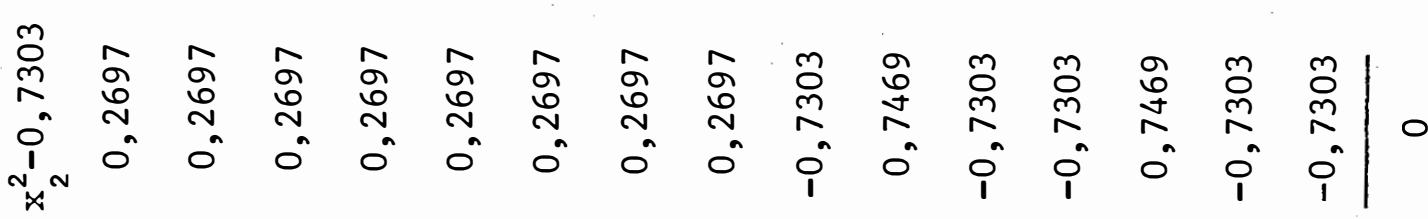

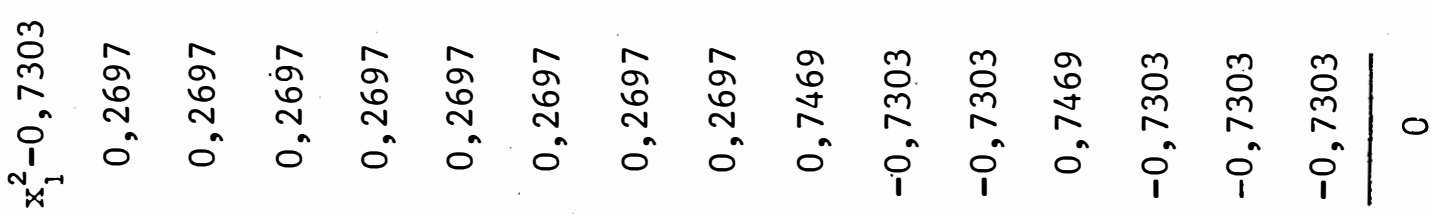

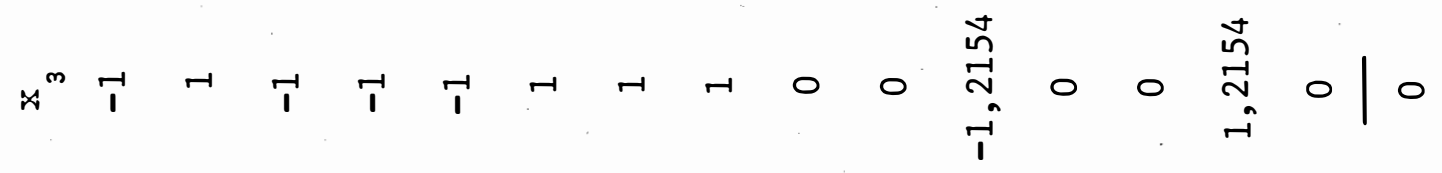

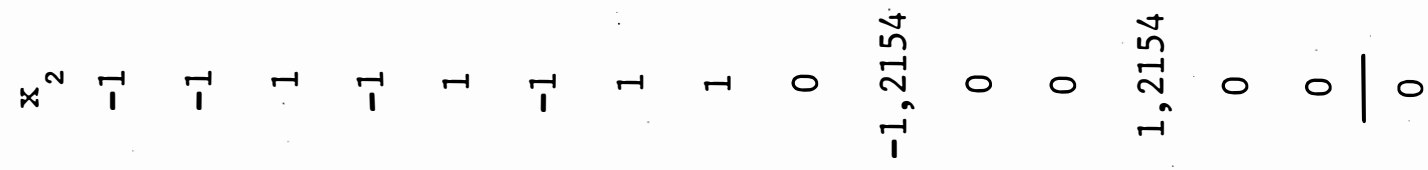

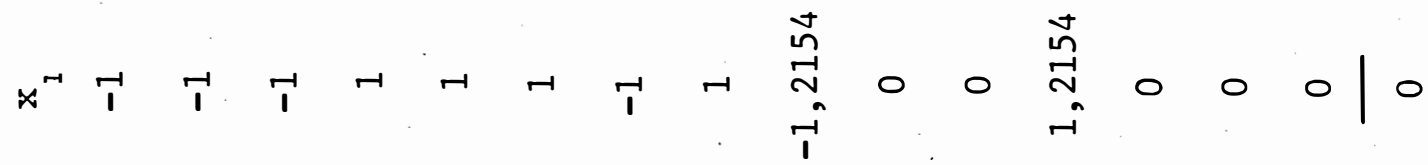

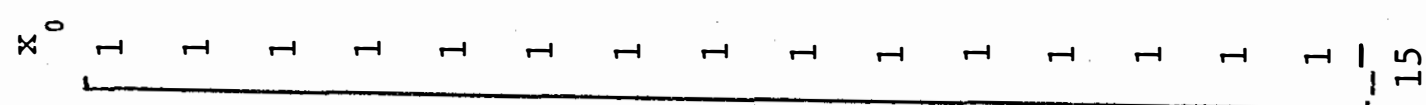




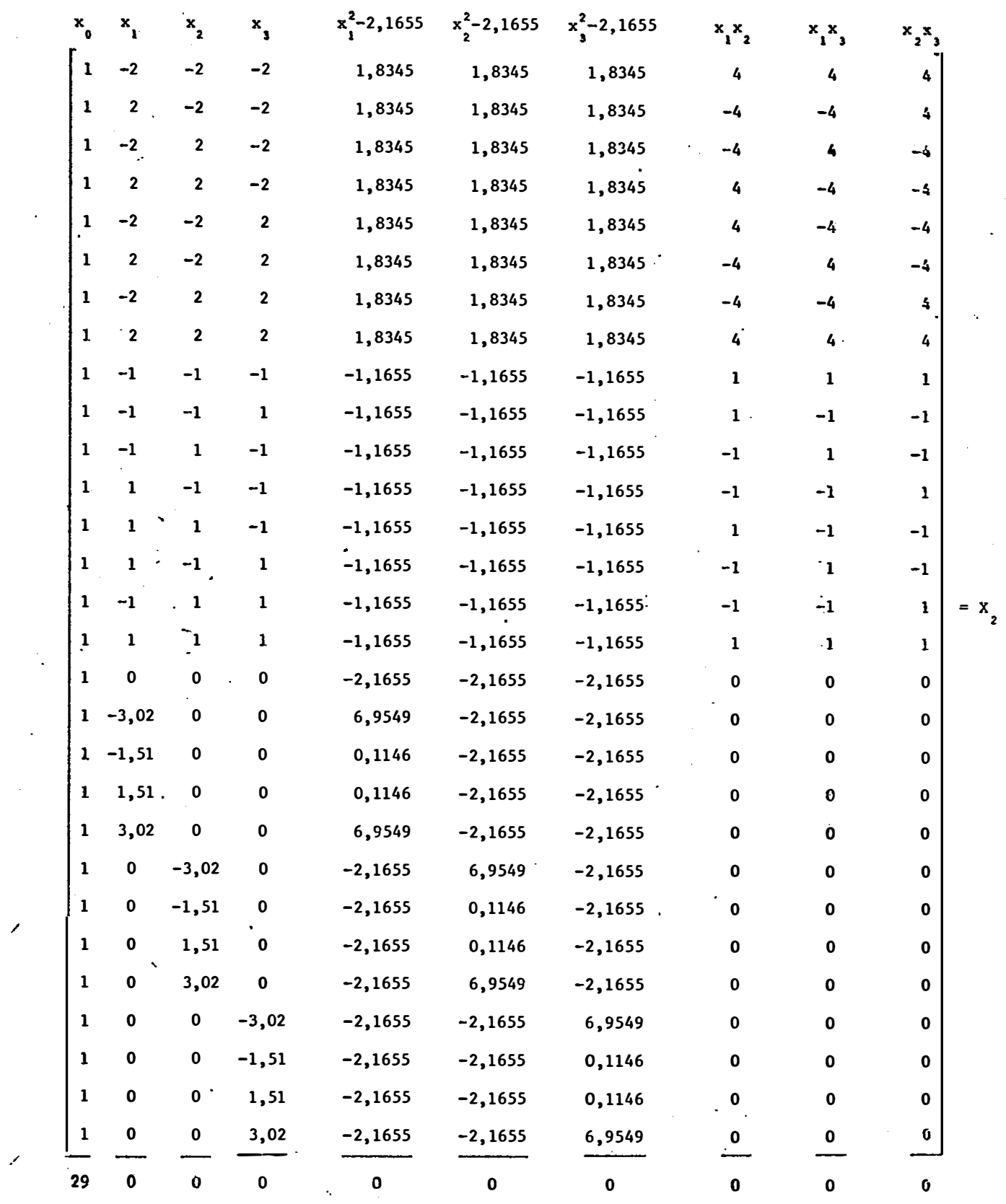




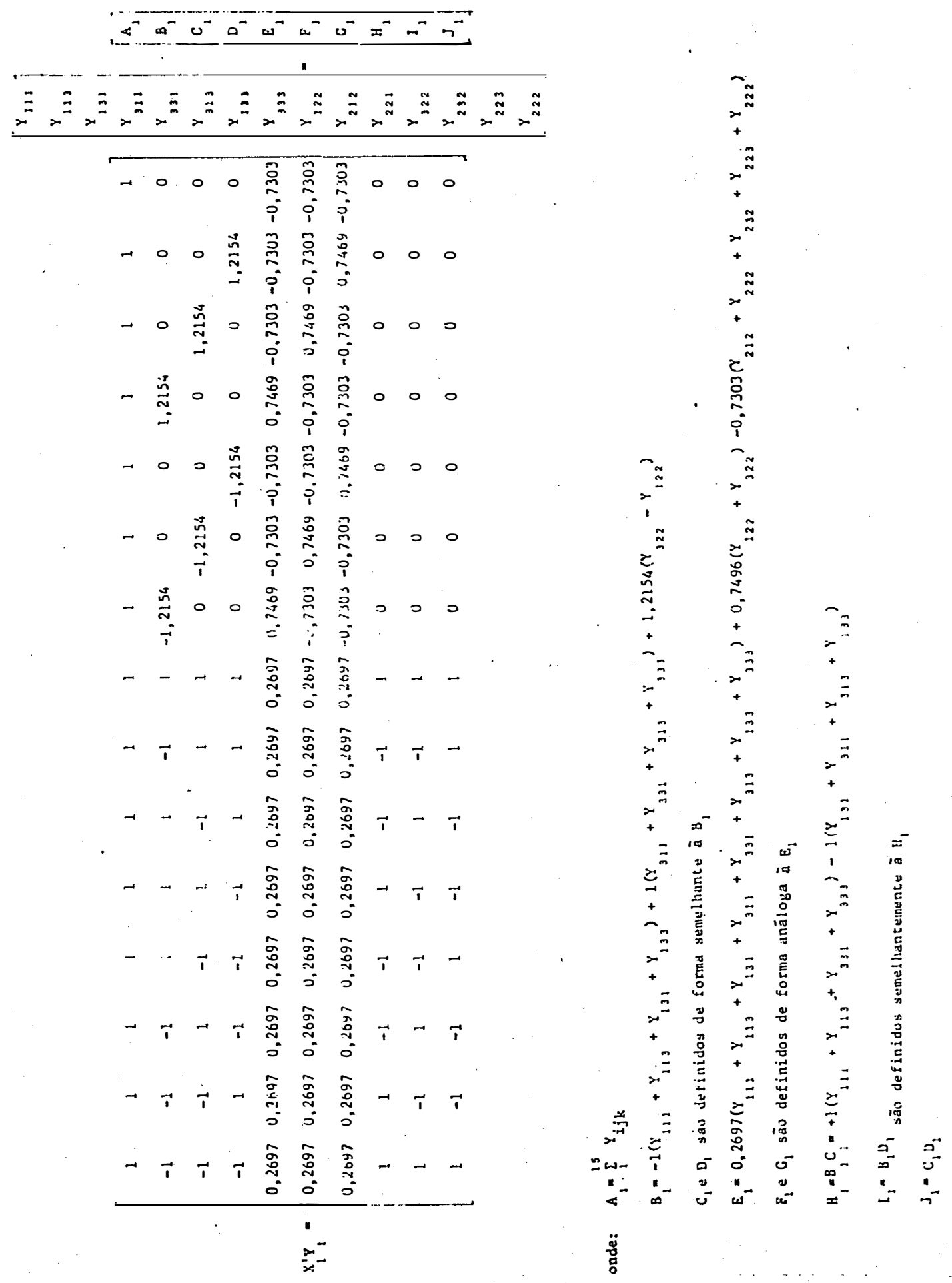




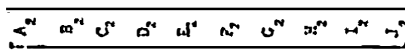

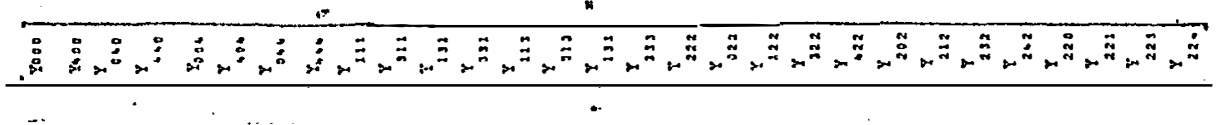

33.

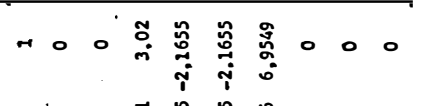

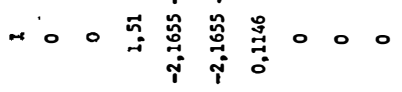

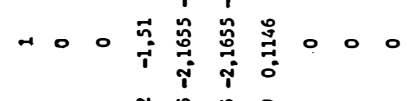

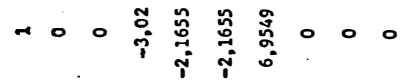

H.

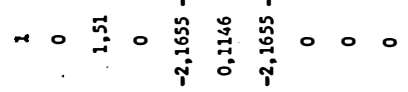

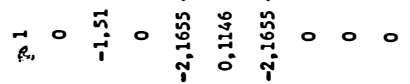

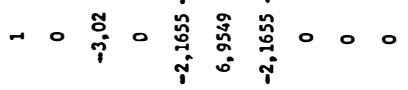

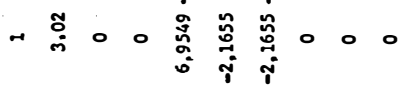

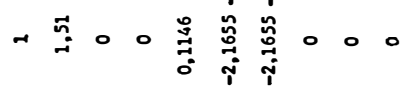

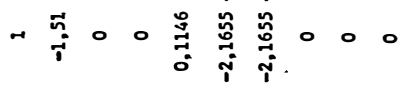

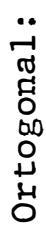

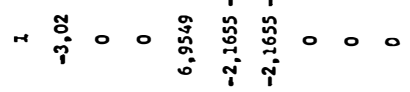

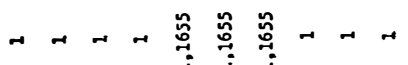

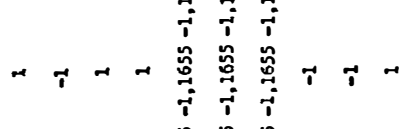

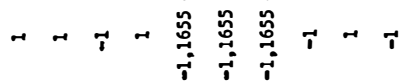

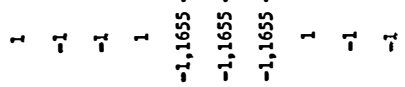

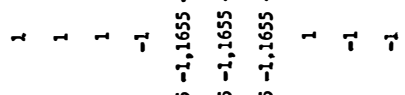

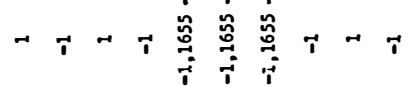

- $+\boldsymbol{\imath}$

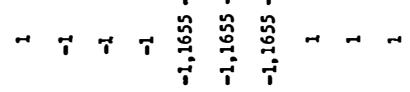

T A

- $น$ N

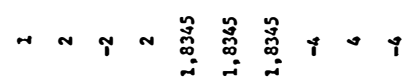

ก

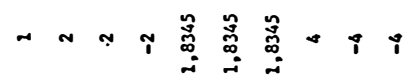

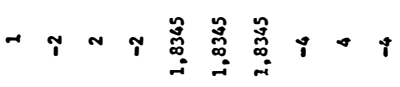

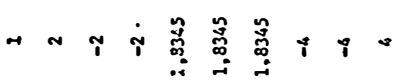

น ช ช

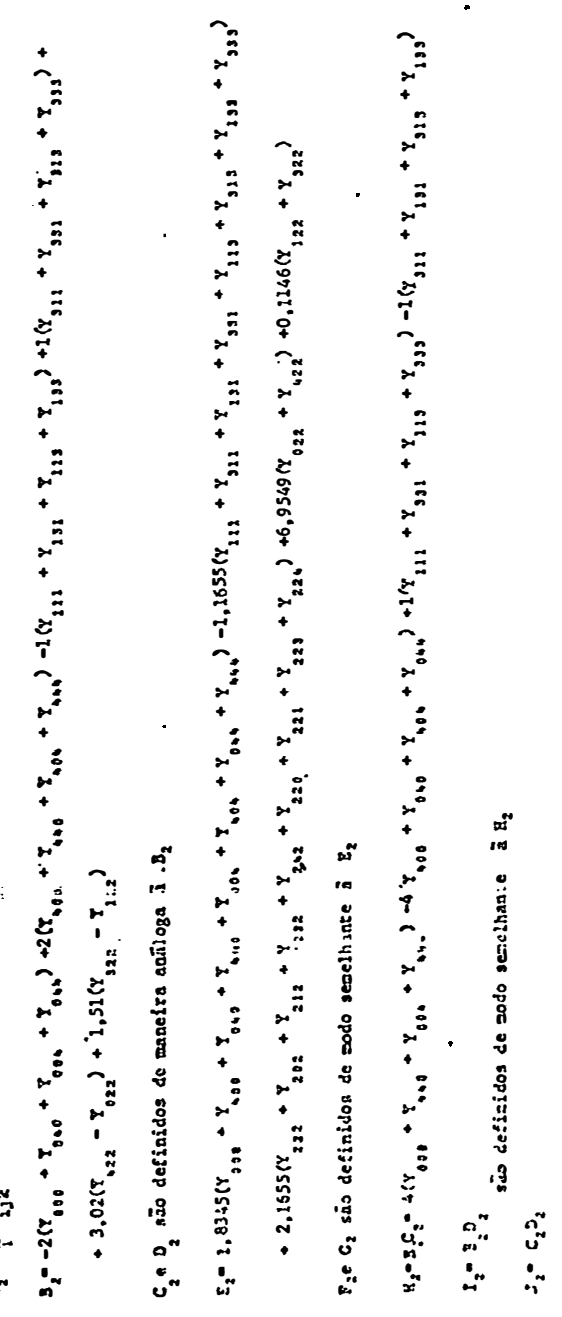


Desse modo, as estimativas dos parâmetros, elementos do vetor $\hat{\beta}$, são:

No delineamento Composto Central Ortogonal:

$$
\hat{B}_{1}=S_{1}^{-1} X_{1}^{\prime} Y_{1}=\left[\begin{array}{c}
\hat{a}_{0} \\
\hat{a}_{1} \\
\hat{a}_{2} \\
\hat{a}_{3} \\
\hat{a}_{11} \\
\hat{a}_{22} \\
\hat{a}_{33} \\
\hat{a}_{12} \\
\hat{a}_{13} \\
\hat{a}_{23} \\
\hat{a}_{23}
\end{array}\right]=\left[\begin{array}{cc}
A_{1} \div 15 \\
0,0913 B_{1} \\
0,0913 C_{1} \\
0,0913 D_{1} \\
0,2291 E_{1} \\
0,2291 F_{1} \\
0,2291 G_{1} \\
H_{1} \div 8 \\
I_{1} \div 8 \\
J_{1} \div 8
\end{array}\right]
$$

No delineamento Duplo Composto Central Ortogonal: 


$$
\widehat{\beta}_{2}=S_{2}^{-1} X_{2}^{\prime} Y_{2}=\left[\begin{array}{c}
b_{0} \\
b_{1} \\
b_{2} \\
b_{3} \\
b_{11} \\
b_{22} \\
b_{33} \\
b_{12} \\
b_{13} \\
b_{23}
\end{array}\right]=\left[\begin{array}{ccc}
A_{2} \div 29 \\
0,0159 B_{2} \\
0,0159 C_{2} \\
0,0159 D_{2} \\
0,005657 E_{2} \\
0,005657 F_{2} \\
0,005657 G_{2} \\
\mathrm{H}_{2} \div 136 \\
I_{2} \div 136 \\
J_{2} \div 136
\end{array}\right]
$$

\subsubsection{Anālise da Variância}

A redução na soma de quadrados, devida à regressão, é dada por:

$$
\text { S.Q.Regressão }=\widehat{B}^{\prime} X^{\prime} Y-C \text {, onde } C=\text { correção. }
$$

Para o delineamento Composto Central Ortogonal tem-se:

$$
S \cdot Q \cdot \operatorname{Reg}=\hat{B}_{1}^{\prime} X_{1}^{\prime} Y_{1}-C_{1} \text { onde } C_{1}=\frac{\left(\sum_{1}^{15} Y_{i j k}\right)^{2}}{15}=\frac{A_{1}^{2}}{15}
$$




$$
\begin{aligned}
& \text { SQReg. }=\frac{1}{15} A_{I}^{2}+0,0913 B_{1}^{2}+0,913 C_{1}^{2}+0,0193 D_{1}^{2}+0,2291 E_{1}^{2}+ \\
& +0,2291 \mathrm{~F}_{1}^{2}+0,2291 \mathrm{G}_{\mathrm{I}}^{2}+\frac{1}{8} \mathrm{H}_{1}^{2}+\frac{1}{8} \mathrm{I}_{1}^{2}+ \\
& +\frac{1}{8} J_{1}^{2}-\frac{1}{15} A_{1}^{2} \\
& \mathrm{SQReg} \cdot=\mathrm{SQ} \hat{\mathrm{a}}_{0}+\mathrm{SQ} \hat{\mathrm{a}}_{1}+\mathrm{SQ} \hat{\mathrm{a}}_{2}+\mathrm{SQ} \hat{\mathrm{a}}_{3}+\mathrm{SQ} \hat{\mathrm{a}}_{11}+\mathrm{SQ} \hat{\mathrm{a}}_{22}+\mathrm{SQ} \hat{\mathrm{a}}_{33}+ \\
& +S Q \hat{a}_{12}+S Q \hat{a}_{13}+S Q \hat{a}_{23}-C_{1}
\end{aligned}
$$

o quadro da análise de variância serä: 


\begin{tabular}{|c|c|c|}
\hline C. Variação & G.L. & $S \cdot Q$. \\
\hline Efeito $\hat{a}_{0}$ (média) & 1 & $S Q \widehat{a}_{0}$ \\
\hline Efeito $\vec{a}_{1}$ & 1 & $\mathrm{SQ}_{1}$ \\
\hline Efeito $\hat{\mathrm{a}}_{2}$ & 1 & $\mathrm{SQ}_{\mathrm{a}}$ \\
\hline Efeito $\widehat{a}_{3}$ & 1 & $\mathrm{SQ}_{3} \widehat{\mathrm{a}}_{3}$ \\
\hline Efeito $\hat{a}_{11}$ & 1 & $\mathrm{SQ}_{11}$ \\
\hline Efeito $\hat{\mathrm{a}}_{22}$ & 1 & $\mathrm{SQ}_{2 \cdot 2}$ \\
\hline Efeito $\hat{\mathrm{a}}_{3 \mathbf{3}}$ & 1 & $\mathrm{SQ}_{33}$ \\
\hline Efeito $\hat{\mathrm{a}}_{12}$ & 1 & $\mathrm{SQ}_{12}$ \\
\hline Efeito $\hat{a}_{13}$ & 1 & $\mathrm{SQ}_{13}$ \\
\hline Efeito $\ddot{a}_{23}$ & 1 & $\mathrm{SQ}_{23}$ \\
\hline Regressão & 10 & $\hat{B}_{1} X_{1}^{\prime} Y_{1}$ \\
\hline Desvios de Regressão & 4 & por dif. \\
\hline Tratamentos & 14 & maneira usual \\
\hline Resíduo & $\mathrm{N}-15$ & por dif. \\
\hline
\end{tabular}

Para o delineamento Duplo Composto Centra1 Ortogona1, tem-se:

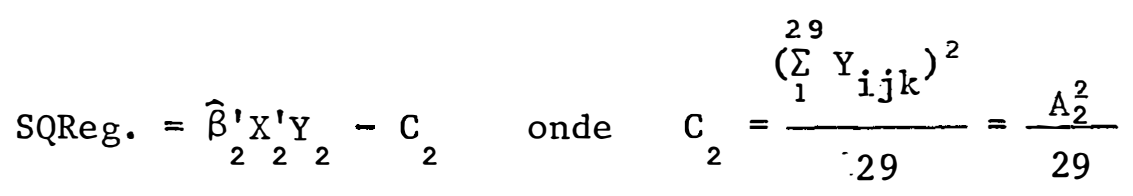




$$
\begin{aligned}
& \mathrm{SQReg} \cdot=\frac{1}{29} \mathrm{~A}_{2}^{2}+0,0159 \mathrm{~B}_{2}^{2}+0,0159 \mathrm{C}_{2}^{2}+0,0159 \mathrm{D}_{2}^{2}+0,00565 \mathrm{E}_{2}^{2}+ \\
& +0,00565 \mathrm{~F}_{2}^{2}+0,00565 \mathrm{G}_{2}^{2}+\frac{1}{136} \mathrm{H}_{2}^{2}+\frac{1}{136} \mathrm{I}_{2}^{2}+ \\
& +\frac{1}{136} \mathrm{~J}_{2}^{2}-\frac{1}{29} \mathrm{~A}_{2}^{2} \\
& \mathrm{SQReg} \cdot=\mathrm{SQb}_{0}+\mathrm{SQb}_{1}+\mathrm{SQb}_{2}+\mathrm{SQb}_{3}+\mathrm{SQb}_{11}+\mathrm{SQ}_{22}+\mathrm{SQb}_{33}+ \\
& \mathrm{SQ}_{12}+\mathrm{SQ} \widehat{b}_{13}+\mathrm{SQb}_{23}-\mathrm{C}_{2}
\end{aligned}
$$

0 quadro de anālise de variância serā: 


\begin{tabular}{|c|c|c|}
\hline C. Variação & G.L. & S.Q. \\
\hline Efeito $b_{0} \quad$ (média) & 1 & $S \hat{Q}_{0}$ \\
\hline Efeito $\bar{b}_{1}$ & 1 & $S Q \widehat{b}_{1}$ \\
\hline Efeito $\mathrm{b}_{2}$ & 1 & $\mathrm{SQb}_{2}$ \\
\hline Efeito $\bar{b}_{3}$ & 1 & $\mathrm{SQb}_{3}$ \\
\hline Efeito $\hat{b}_{11}$ & 1 & $\mathrm{SQ}_{11}$ \\
\hline Efeito $\bar{b}_{22}$ & 1 & $\mathrm{SQB}_{22}$ \\
\hline Efeito $\widehat{b}_{3 з}$ & 1 & $\mathrm{SQ}_{33}$ \\
\hline Efeito $\bar{b}_{12}$ & 1 & $\mathrm{SQ}_{12}$ \\
\hline Efeito $b_{13}$ & 1 & $\mathrm{SQb}_{13}$ \\
\hline Efeito $\bar{b}_{23}$ & 1 & $\mathrm{SQB}_{23}$ \\
\hline Regressão & 10 & $\hat{\beta}_{2}^{\prime} X_{2}^{\prime} Y_{2}^{\prime}$ \\
\hline Desvios de Regressão & 18 & por dif. \\
\hline Tratamentos & 28 & maneira usual \\
\hline Resíduo & $N-29$ & por dif. \\
\hline $\mathrm{T} \circ \mathrm{t}$ a 1 & $N-1$ & $\sum_{1}^{29} Y_{i j k}^{2}-C_{2}$ \\
\hline
\end{tabular}

As hipóteses de nulidade relativas às diferentes cau sas de variação são testadas através da prova de F, utilizando o Q.M. Res. como denominador para todas as fontes. 
4.1.4. Variâncias e Covariâncias das Estimativas dos Parâmetros

A matriz de dispersão (D) ou matriz das variâncias e

covariâncias de $\hat{\beta}$ é obtida a partir da matriz $\mathrm{s}^{-1}$. Assim, através da igualdade $\mathrm{D}=\mathrm{S}^{-1} \mathrm{O}^{2}$ têm-se as variâncias (elementos da diagonal prin cipa1) e as covariâncias (elementos fora da diagonal principal) das estimativas dos parâmetros.

Como em experimentação $\sigma^{2}$ é desconhecido, trabalha-se com sua estimativa imparcial $\mathrm{s}^{2}=$ Q.M.Res., obtendo-se, assim, as variâncias e covariâncias estimadas.

$\underline{\text { Para o modelo Composto Central Ortogonal: }}$

$$
\begin{aligned}
& \mathrm{V}\left(\hat{\mathrm{a}}_{0}\right)=1 / 15 \sigma^{2} \quad \widehat{\mathrm{V}}\left(\hat{\mathrm{a}}_{0}\right)=1 / 15 \mathrm{~s}^{2} \\
& \mathrm{~V}\left(\hat{\mathrm{a}}_{\mathrm{i}}\right)=0,0913 \sigma^{2} \quad \hat{\mathrm{v}}\left(\hat{\mathrm{a}}_{\mathrm{i}}\right)=0,0913 \mathrm{~s}^{2} \quad \mathrm{i}=1,2,3 \\
& \mathrm{~V}\left(\hat{\mathrm{a}}_{\mathrm{ii}}\right)=0,2291 \sigma^{2} \quad \widehat{\mathrm{v}}\left(\hat{\mathrm{a}}_{i \mathrm{i}}\right)=0,2291 \mathrm{~s}^{2} \quad 1=1,2,3 \\
& v\left(\hat{a}_{i j}\right)=1 / 8 \sigma^{2} \quad \hat{v}\left(\hat{a}_{i j}\right)=1 / 8 s^{2} \quad i=1,2 ; j=2,3 \\
& I \neq J \\
& j \neq j^{\prime}=1,2,3
\end{aligned}
$$




$$
\begin{aligned}
& \mathrm{V}\left(\widehat{\mathrm{b}}_{0}\right)=1 / 29 \sigma^{2} \quad \hat{\mathrm{V}}\left(\widehat{\mathrm{b}}_{0}\right)=1 / 29 \mathrm{~s}^{2} \\
& v\left(\widehat{b}_{i}\right)=0,0159 \sigma^{2} \quad \hat{\mathrm{V}}\left(\widehat{b}_{i}\right)=0,0159 \mathrm{~s}^{2} \quad i=1,2,3 \\
& v\left(\widehat{b}_{i i}\right)=0,005657 \sigma^{2} \quad \hat{\mathrm{v}}\left(\mathrm{b}_{i i}\right)=0,005657 \mathrm{~s}^{2} \quad i=1,2,3 \\
& v\left(\hat{b}_{i j}\right)=1 / 136 \sigma^{2} \quad \hat{V}\left(\hat{b}_{i j}\right)=1 / 136 s^{2} \quad i=1,2 ; j=2,3 \\
& \mathbf{i} \neq \mathbf{j} \\
& \text { e as } \operatorname{Cov}\left(\widehat{b}_{i j}, \widehat{b}_{i^{\prime} j^{\prime}}\right)=0 \quad i \neq i^{\prime}=1,2,3 \\
& j \neq j^{\prime}=1,2,3
\end{aligned}
$$

\subsection{Comparação Entre as Variāncias}

4.2.1. Eficiência do Delineamento Duplo Composto Central Ortogonal em Relação ao Delineamento Composto Central Ortogonal

Pelo fato do número de tratamentos ser diferente nos dois modelos, não é correto comparar simplesmente as variâncias anterio res. Para a resolução desse problema, BOX e WILSON (1951) propuseram um processo de comparação quanto a precisão das estimativas dos parâmetros, confrontando

$$
\mathrm{N}_{1} \mathrm{~V}_{1} \quad \operatorname{com} \mathrm{N}_{2} \mathrm{~V}_{2}
$$

sendo $\mathrm{N}_{1}$ e $\mathrm{N}_{2}$ os números das observações

$V_{1}$ e $V_{2}$ variâncias das estimativas a serem comparadas. 
Com base neste processo, tem-se, neste caso, que multí plicar as variâncias das estimativas do delineamento Composto Central Ortogonal por $\mathrm{N}_{1}=15$ e as do Duplo Composto Central Ortogonal por $\mathrm{N}_{2}=29$.

Tínha-se a seguinte situação:

$$
\begin{array}{cc}
\text { C.C.O. } & \text { D.C.C.O. } \\
v\left(\hat{a}_{i}\right)=0,0913 \sigma^{2} & v\left(\hat{b}_{i}\right)=0,0159 \sigma^{2} \\
v\left(\hat{a}_{i j}\right)=0,2291 \sigma^{2} & v\left(\hat{b}_{i j}\right)=0,005657 \sigma^{2} \\
v\left(\hat{a}_{i j}\right)=1 / 8 \sigma^{2} & v\left(\hat{b}_{i j}\right)=1 / 136 \sigma^{2}
\end{array}
$$

Fazendo o ajuste para número de observações, tem-se:

$$
\text { C.C.O. }
$$

$\mathrm{v}\left(\hat{\mathrm{a}}_{\mathrm{i}}\right)=(15)\left(0,0913 \sigma^{2}\right)=1,3695 \sigma^{2}$

$\mathrm{v}\left(\hat{\mathrm{a}}_{\mathrm{ii}}\right)=(15)\left(0,2291 \sigma^{2}\right)=3,4365 \sigma^{2}$

$v\left(\hat{a}_{i j}\right)=15 / 8 \sigma^{2}=1,8550 \sigma^{2}$
D.C.C.O.

$$
\begin{aligned}
& v\left(\widehat{\sigma}_{i}\right)=(29)\left(0,0159 \sigma^{2}\right)=0,4611 \sigma^{2} \\
& v\left(\widehat{b}_{i i}\right)=(29)\left(0,005657 \sigma^{2}\right)=0,1641 \sigma^{2} \\
& v\left(\widehat{b}_{i j}\right)=29 / 136 \sigma^{2}=0,2133 \sigma^{2}
\end{aligned}
$$

Entretanto, a comparação ainda não é correta, pois o "spread" (expansão), nos dois delineamentos, não é igual. A medida do "spread" é dada por

$$
\mathrm{s}^{2}=\frac{\mathrm{u} \mathrm{x}_{\mathrm{iu}}^{2}}{\mathrm{~N}}
$$

(MYERS, 1971, pág. 135), que é o 20 momento do delineamento. 
Fazendo o ajuste de escala:

Para o delineamento Composto Central Ortogonal,

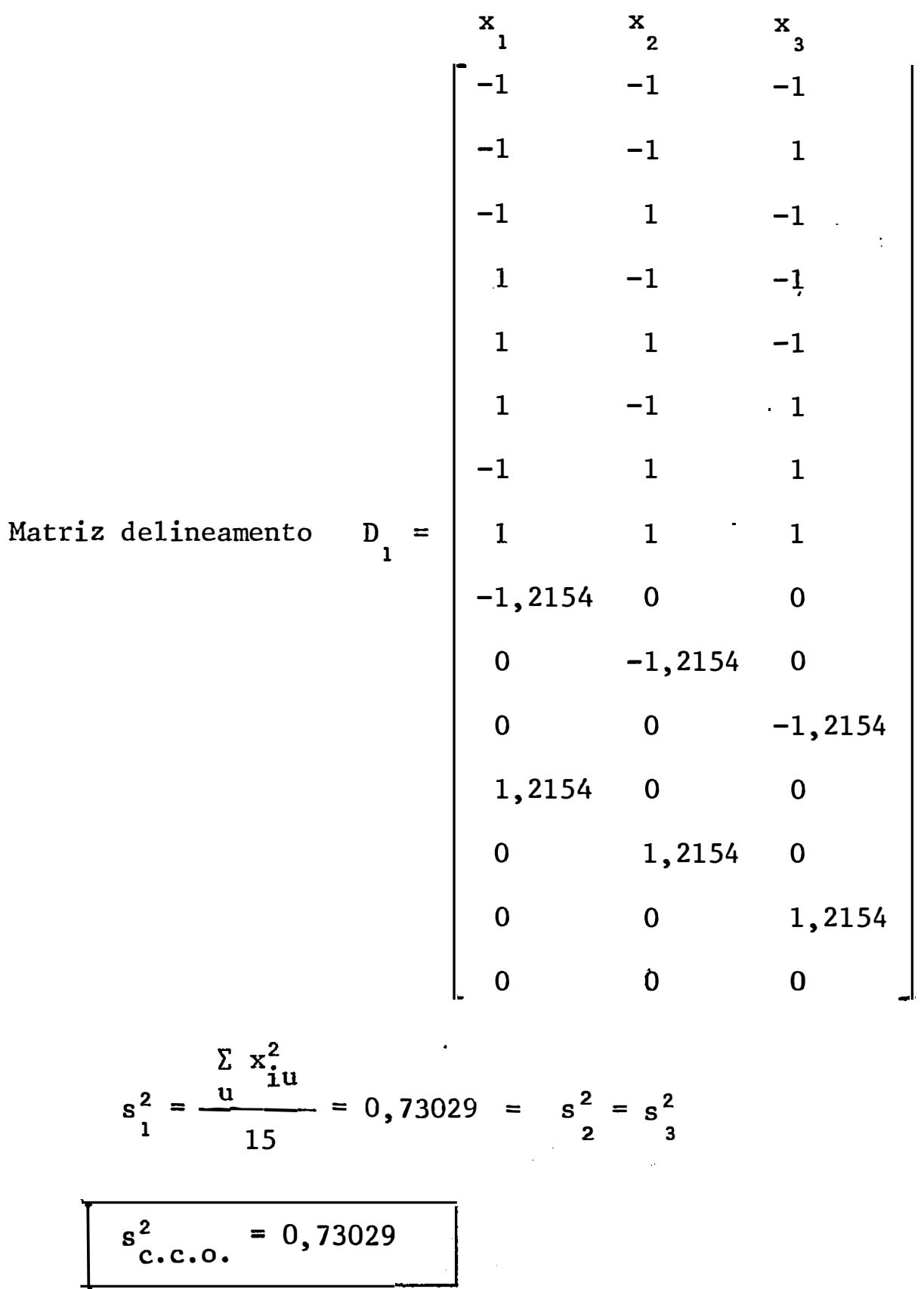


Para o delineamento Duplo Composto Central Ortogonal

$$
\begin{aligned}
& \text { Matriz Delineamento } \quad D_{2}=\left[\begin{array}{ccc}
x_{1} & x_{2} & x_{3} \\
-2 & -2 & -2 \\
2 & -2 & -2 \\
-2 & 2 & -2 \\
2 & 2 & -2 \\
-2 & -2 & 2 \\
2 & -2 & 2 \\
-2 & 2 & 2 \\
2 & 2 & 2 \\
-1 & -1 & -1 \\
1 & -1 & -1 \\
-1 & 1 & -1 \\
1 & 1 & -1 \\
-1 & -1 & 1 \\
1 & -1 & 1 \\
-1 & 1 & 1 \\
1 & 1 & 1 \\
0 & 0 & 0 \\
-3,02 & 0 & 0 \\
-1,51 & 0 & 0 \\
1,51 & 0 & 0 \\
3,02 & 0 & 0 \\
0 & -3,02 & 0 \\
0 & -1,51 & 0 \\
0 & 1,51 & 0 \\
0 & 3,02 & 0 \\
0 & 0 & -3,02 \\
0 & 0 & -1,51 \\
0 & 0 & 1,51 \\
0 & 0 & 3,02
\end{array}\right] \text {. } \\
& s_{1}^{2}=\frac{\sum x_{i u}^{2}}{29}=s_{2}^{2}=s_{3}^{2} \\
& \mathrm{~s}_{\mathrm{d} . \mathrm{c.c.o.}}^{2}=2,16555
\end{aligned}
$$


Desta forma, ao se comparar as variâncias entre os de lineamentos deve-se multiplicar por $s^{2}$ as variâncias das estimativas dos parâmetros do efeito linear e por $s^{4}$ dos efeitos quadráticos e in terações:

Para D.C.C.O.

$$
\begin{aligned}
& V\left(\widehat{b}_{i}\right)=s^{2}\left(0,4611 \sigma^{2}\right)=(2,1655)\left(0,4611 \sigma^{2}\right)=0,9985 \sigma^{2} \simeq \sigma^{2} \\
& v\left(b_{i i}\right)=s^{4}\left(0,1641 \sigma^{2}\right)=(2,1655)^{2}\left(0,1641 \sigma^{2}\right)=0,7695 \sigma^{2} \\
& V\left(b_{i j}\right)=s^{4}\left(0,2133 \sigma^{2}\right)=\sigma^{2}
\end{aligned}
$$

Para C.C.O.

$$
\begin{aligned}
& v\left(\hat{a}_{i}\right)=s^{2}\left(1,3695 \sigma^{2}\right)=(0,73029)\left(1,3695 \sigma^{2}\right)=\sigma^{2} \\
& v\left(\hat{a}_{i i}\right)=s^{4}\left(3,4365 \sigma^{2}\right)=(0,73029)^{2}\left(3,4365 \sigma^{2}\right)=1,83278 \sigma^{2} \\
& v\left(\hat{a}_{i j}\right)=s^{4}\left(1,855 \sigma^{2}\right) \simeq \sigma^{2}
\end{aligned}
$$

A eficiência $E$ entre a variância dos parâmetros esti mados b's do D.C.C.O. e dos a's do C.C.O. é dada por:

$$
E\left(-\frac{\text { D.C.C.O. }}{\text { C.C.O. }}\right)=\frac{(\text { Variância a's) }}{(\text { Variância b's) }}
$$

Assim, para os efeitos lineares e interações:

$$
\mathrm{E}=1,00 \text {, }
$$


e para os efeitos quadráticos:

$$
E=\frac{1,83278 \sigma^{2}}{0,7695 \sigma^{2}}=2,38
$$

Por outro lado, segundo critério de MYERS (1971, pág. 136), o "spread" (expansão) deve ser igual nos dois delineamentos; para tanto usa-se o escalonamento convencional dado por:

$$
\sum_{u=1}^{N} x_{i u}^{2}=N \quad \text { e } \quad \sum_{u=1}^{N} x_{i u}=0 \quad(i=1, \ldots, k)
$$

Assim, para o D.C.C.O. deve-se ter $\sum_{u=1}^{15} x_{i u}^{2}=15$. Como $\sum_{u=1} x_{i u}^{2}=10,9544$, deve-se ter uma constante ' $k$ tal que: $k \cdot \sum x_{i u}^{2}=15$ donde $k=1,3693$ e $\mathrm{k}^{1 / 2}=1,1702$.

Desta forma, deve-se multiplicar cada coluna da matriz $\mathrm{D}_{1}$ do delineamento Composto Centra1 Ortogona1 por 1,1702 obtendo-se: 


$$
D_{1}=\left[\begin{array}{ccc}
-1,1702 & -1,1702 & -1,1702 \\
-1,1702 & -1,1702 & 1,1702 \\
-1,1702 & 1,1702 & -1,1702 \\
1,1702 & -1,1702 & -1,1702 \\
1,1702 & 1,1702 & -1,1702 \\
1,1702 & -1,1702 & 1,1702 \\
-1,1702 & 1,1702 & 1,1702 \\
1,1702 & 1,1702 & 1,1702 \\
-1,4223 & 0 & 0 \\
0 & -1,4223 & 0 \\
0 & 0 & -1,4223 \\
1,4223 & 0 & 0 \\
0 & 1,4223 & 0 \\
0 & 0 & 1,4223 \\
0 & 0 & 0
\end{array}\right]
$$

onde se verificam as igualdades: $\quad \sum_{1}^{15} x_{i u}^{2}=15$

$$
\sum_{1}^{15} x_{i u}=0
$$

Para o D.C.C.O. deve-se ter $\sum_{u=1}^{29} x_{i u}^{2}=29$ e $\sum_{u} x_{i u}=0$. Como $\sum x_{i u}^{2}=62,8010$, a constante $k$ deverá ser igual a 0,4618 , donde $\mathrm{k}^{1 / 2}=0,6795$. Multiplicando-se cada coluna da matriz $\mathrm{D}_{2}$ do delinea mento por 0,6795 obtēm-se: 
48.

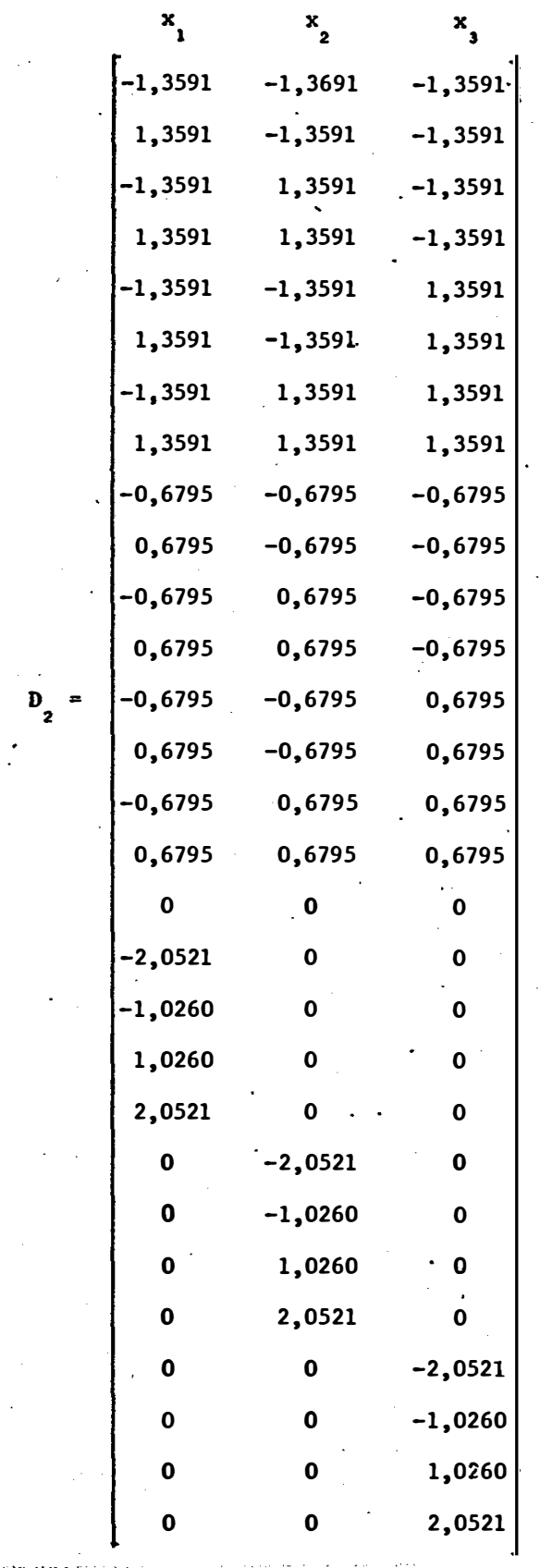


onde, também, se verificam $\sum_{u=1}^{29} x_{i u}^{2}=29$ e $\underset{u=1}{29} x_{i u}=0$.

Para comparar-se a eficiência entre os delineamentos prẹ cisa-se das variâncias dos parâmetros estimados e para tanto precisa-se da matriz $\mathrm{X}$ de cada um dos delineamentos.

Assim, tem-se:

Para o C.C.0. a matriz $X$ passa a ser:

\begin{tabular}{|c|c|c|c|c|c|c|c|c|c|}
\hline 0 & $x_{1}$ & $x_{2}$ & $x_{3}$ & $\left(x_{1}^{2}-c\right)$ & $\left(x_{2}^{2}-c\right)$ & $\left(x_{3}^{2}-c\right)$ & $x_{1} x_{2}$ & $x_{1} x_{3}$ & $x_{2} x_{3}$ \\
\hline 1 & $-1,1702$ & $-1,1702$ & $-1,1702$ & 0,3694 & 0,3694 & 0,3694 & 1,3694 & 1,3694 & 1,3694 \\
\hline 1 & $-1,1702$ & $-1,1702$ & 1,1702 & 0,3694 & 0,3694 & 0,3694 & 1,3694 & $-1,3694$ & $-1,3694$ \\
\hline 1 & $-1,1702$ & 1,1702 & $-1,1702$ & 0,3694 & 0,3694 & 0,3694 & $-1,3694$ & 1,3694 & $-1,3694$ \\
\hline 1 & 1,1702 & $-1,1702$ & $-1,1702$ & 0,3694 & 0,3694 & 0,3694 & $-1,3694$ & $-1,3694$ & 1,3694 \\
\hline 1 & $\cdot 1,1702$ & 1,1702 & $-1,1702$ & 0,3694 & $0,3694^{\circ}$ & 0,3694 & $1,3694^{\circ}$ & $-1,3694$ & $-1,3694$ \\
\hline 1 & 1,1702 & $-1,1702$ & 1,1702 & 0,3694 & 0,3694 & 0,3694 & $-1,3694$ & 1,3694 & $-1,3694$ \\
\hline 1 & $-1,1702$ & 1,1702 & 1,1702 & 0,3694 & 0,3694 & 0,3694 & $-1,3694$ & $-1,3694$ & 1,3694 \\
\hline 1 & 1,1702 & 1,1702 & 1,1702 & 0,3694 & 0,3694 & 0,3694 & 1,3694 & $i, 3694$ & 1,3694 \\
\hline 1 & $-1,4223$ & 0 & 0 & 1,0229 & -1 & -1 & 0 & 0 & 0 \\
\hline 1 & 0 & $-1,4223$ & 0 & -1 & 1,0229 & -1 & 0 & 0 & 0 \\
\hline 1 & 0 & 0 & $-1,4223$ & -1 & -1 & 1,0229 & 0 & 0 & 0 \\
\hline 1 & 1,4223 & 0 & 0 & 1,0229 & -1 & -1 & 0 & 0 & 0 \\
\hline 1 & 0 & 1,4223 & 0 & -1 & 1,0229 & -1 & 0 & 0 & 0 \\
\hline 1 & 0 & 0 & 1,4223 & -1 & -1 & 1.0229 & 0 & 0 & 0 \\
\hline 1 & 0 & 0 & 0 & -1 & -1 & -1 & 0 & 0 & 0 \\
\hline
\end{tabular}


A partir da matriz $X_{1}$ constroem-se $X_{1}^{\prime} x_{1}$, não singular, e sua inversa $\left(X_{1}^{\prime} X_{1}\right)^{-1}$

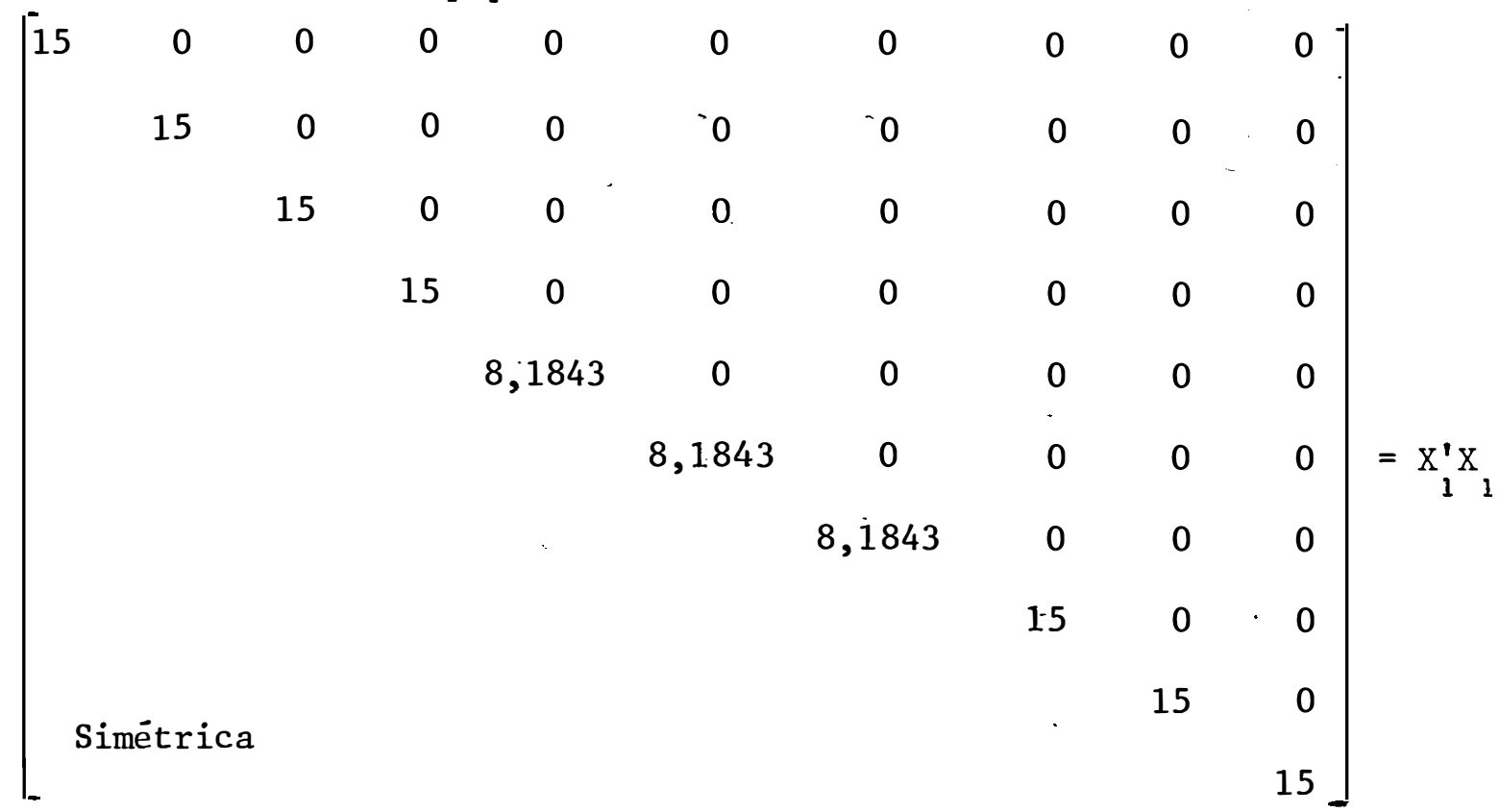

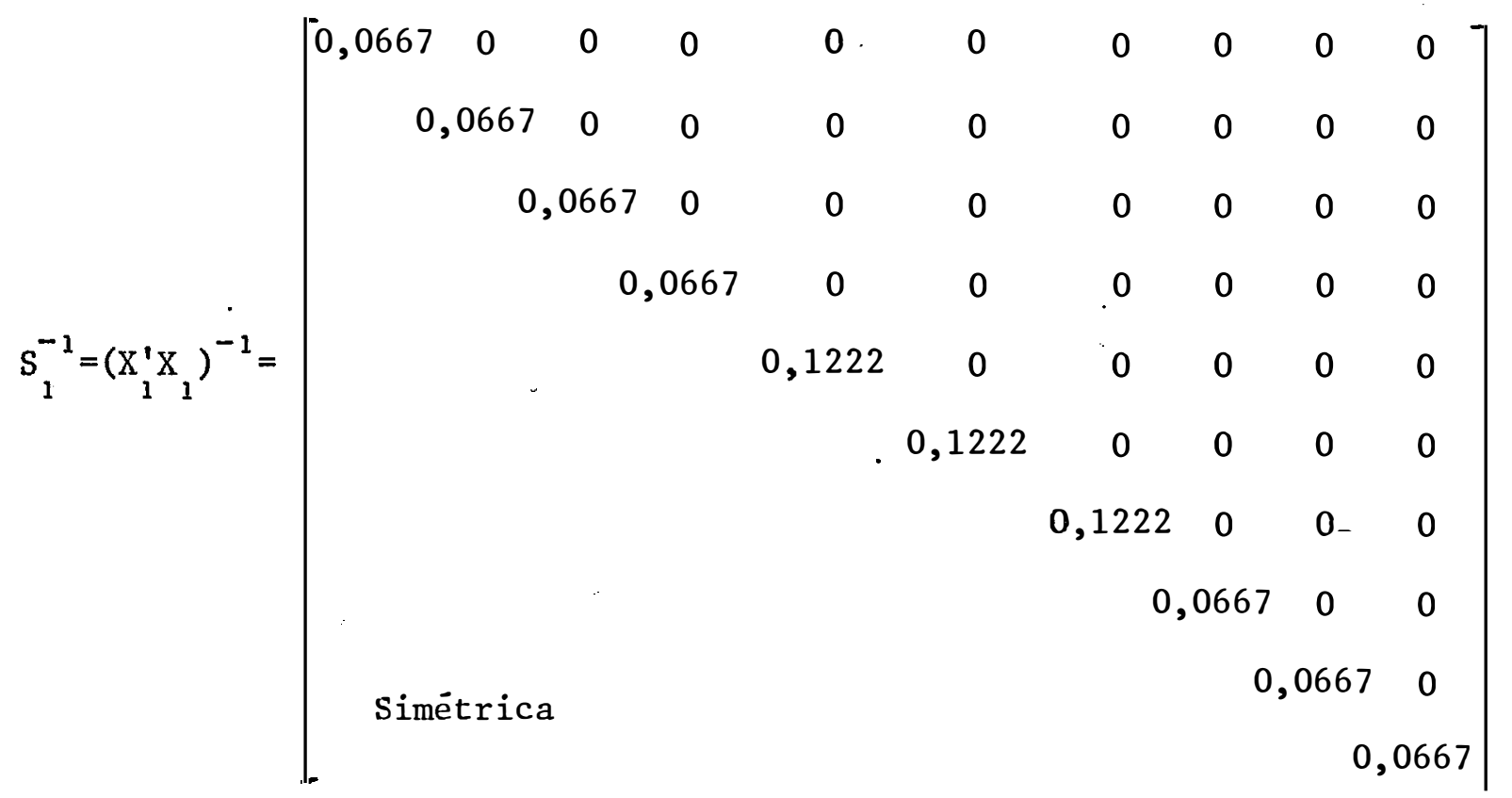


Para o D.C.C.O a matriz $X$ passa a ser:

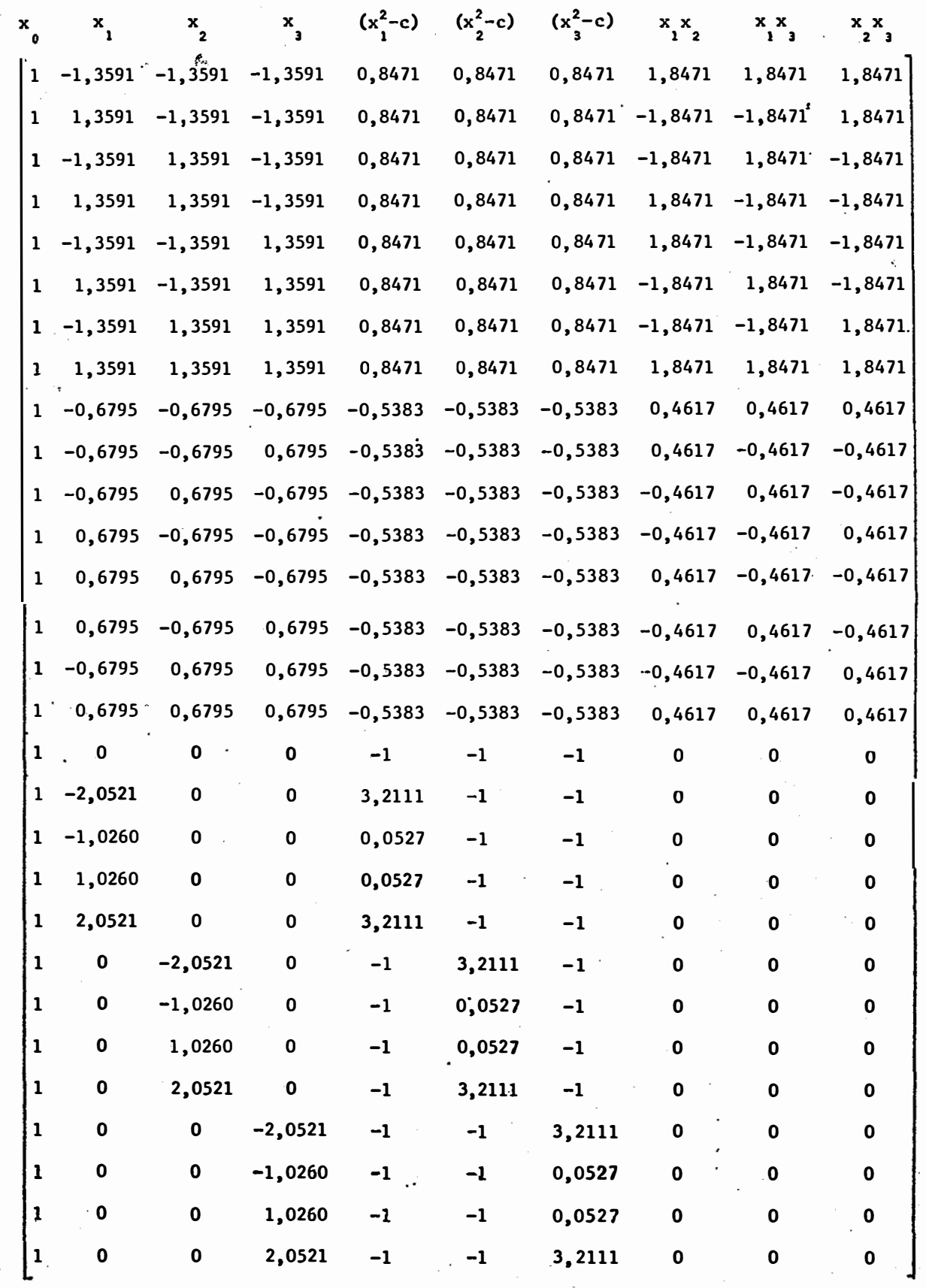




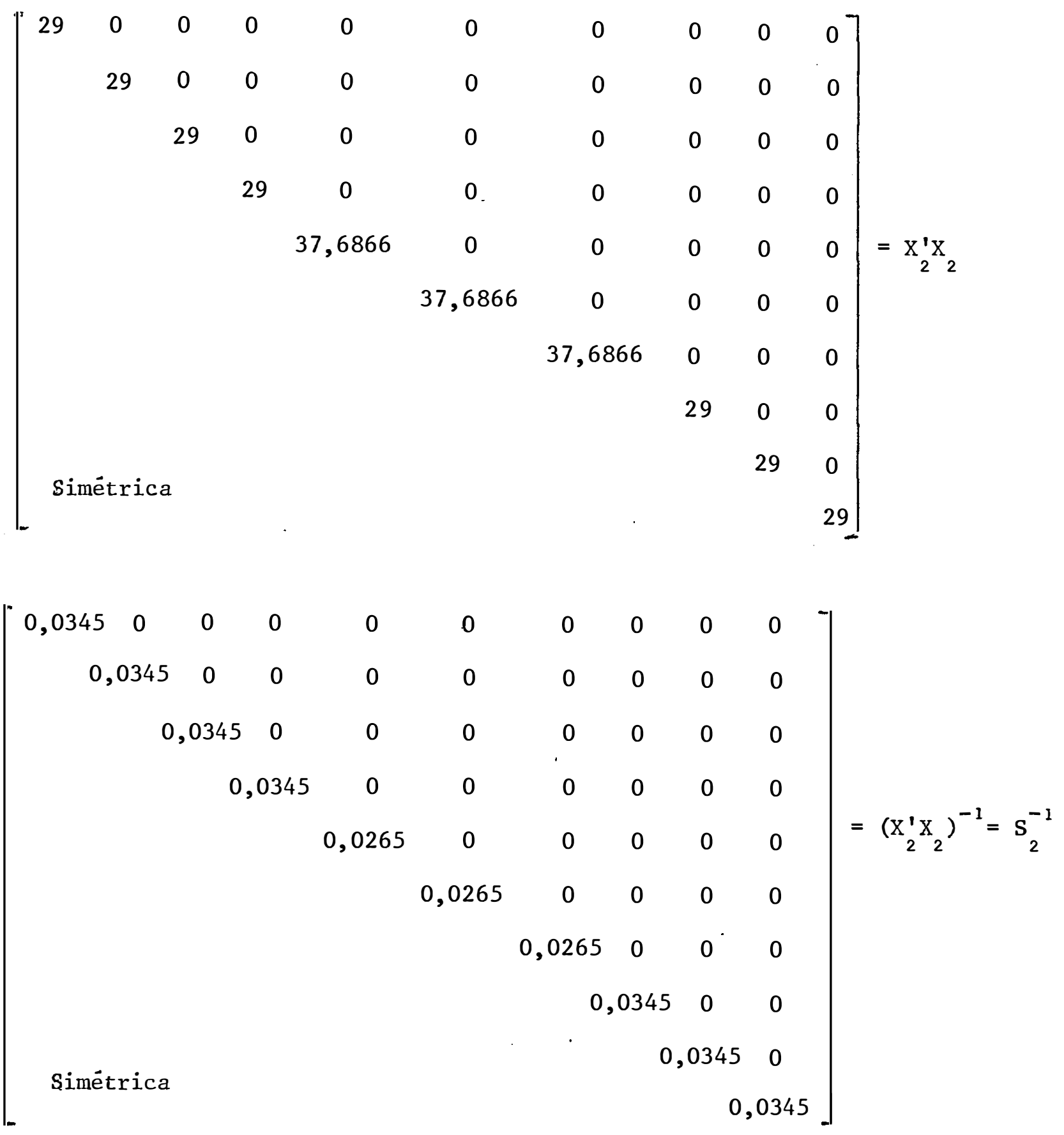


onde, em ambos os delineamentos, $c=1$ pois $\sum_{u=1}^{N}\left(x_{i . u}^{2}-c\right)=0$, o que equivale, simplesmente, a multiplicar-se nas matrizes $\mathrm{X}$ originais, da das na página 28, as colunas dos termos lineares por $\mathrm{k}^{1 / 2}$ e as colunas dos termos quadráticos e interações por $k$.

Agora, podem-se comparar as variâncias, dos parâmetros estimados, entre os delineamentos

\begin{tabular}{c|c}
\hline D.C.C.o. & C.C.o. \\
\hline$v\left(\widehat{b}_{i}\right)=v\left(\widehat{b}_{i j}\right)=\frac{1}{29} \sigma^{2}=0,0345 \sigma^{2}$ & $v\left(\hat{a}_{i}\right)=v\left(\hat{a}_{i j}\right)=\frac{1}{15} \sigma^{2}=0,0667 \sigma^{2}$ \\
$v\left(\left(_{i j}\right)=0,0265 \sigma^{2}\right.$ & $v\left(\hat{a}_{i i}\right)=0,1222 \sigma^{2}$ \\
\hline
\end{tabular}

A eficiência entre a variância dos parâmetros estimados b's do D.C.C.o. e dos a's do C.C.o. é dada dada por:

E $\frac{\text { D.C.C.o. }}{\text { C.C.o. }}=\frac{(\text { Variância a's }) \mathrm{N}_{1}}{\left(\text { Variância b's) } \mathrm{N}_{2}\right.}$.

Para os efeitos lineares e interações

$$
E=\frac{\left(\frac{1}{15} \sigma^{2}\right)}{\left(\frac{1}{29} \sigma^{2}\right)} \cdot\left(\frac{15}{29}\right)=1,00
$$

e para os efeitos quadráticos

$$
E=\underset{0,0265 \sigma^{2}}{\left(\frac{0,1222 \sigma^{2}}{\longrightarrow}\right.} \cdot \underset{29}{\left(\frac{15}{\longrightarrow}\right.}=\frac{1,833}{0,7685}=2,38
$$


4.2.2. Intervalos de Confiança dos Parãmetros

Admitindo-se a hipótese de que os parâmetros têm uma distribuição aproximadamente normal, os extremos de seus intervalos de confiança são calculados como se segue:

$$
\operatorname{I.C.}\left(a_{i j}\right): \hat{a}_{i j} \pm t \sqrt{\widehat{\hat{v}}\left(\hat{a}_{i j}\right)}
$$

onde:

$$
\begin{aligned}
& \hat{a}_{i j} \text { é qualquer um dos parâmetros estimados; } \\
& t \quad \text { è obtido da distribuição teórica de } t \text { ao nível } \alpha / 2 \text { de pro } \\
& \text { babilidade e com o número de graus de liberdade do resíduo. }
\end{aligned}
$$

$$
\text { Assim, serão obtidos os seguintes intervalos: }
$$

Para os parâmetros do C.C.o.

$$
\begin{array}{ll}
\hat{a}_{i} \pm \text { ts } 0,2582 & (i=0,1,2,3) \\
\hat{a}_{i j} \pm \text { ts } 0,3496 & (i=1,2,3) \\
\hat{a}_{i j} \pm \text { ts } 0,2582 & (i=1,2 ; j=2,3 ; i \neq j)
\end{array}
$$

Admitindo o níve1 $95 \%$ de probabilidade e tomando $t=2,78$, tem-se:

$$
\begin{aligned}
& \hat{a}_{i} \pm 0,7178 \mathrm{~s} \\
& a_{i j} \pm 0,9718 \mathrm{~s} \\
& \hat{a}_{i j} \pm 0,7178 \mathrm{~s}
\end{aligned}
$$


Para os parâmetros do D.C.C.0.

$$
\begin{array}{ll}
\mathrm{b}_{i} \pm \text { ts } 0,1857 & (i=0,1,2,3) \\
\mathrm{b}_{i j} \pm \text { ts } 0,1628 & (i=1,2,3) \\
\mathrm{b}_{\mathbf{i j}} \pm \text { ts } 0,1857 & (i=1,2 ; j=2,3 ; i \neq j)
\end{array}
$$

Admitindo o nível $95 \%$ de probabilidade e tomando $t=2,10$, tem-se:

$$
\begin{aligned}
& \widehat{b}_{i} \pm 0,3900 \mathrm{~s} \\
& \widehat{b}_{i i} \pm 0,3418 \mathrm{~s} \\
& \widehat{b}_{i j} \pm 0,3900 \mathrm{~s}
\end{aligned}
$$

4.2.3. Variâncias e Intervalos de Confiança das Estimativas das Produções Estimadas

No Delineamento Composto Central Ortogonal:

Observando a Matriz $\mathrm{x}_{1}$, dada em 4.2.1. verifica-se que os 15 tratamentos se subdividem em 3 grupos distintos, reunindo em cada um os tratamentos que apresentam a mesma expressão da variância da estimativa do $Y$ • Os grupos são assim formados: 
56.

10. Grupo: $111,113,131,311,331,313,133$ e 333;

20. Grupo: 122, 212, 221, 322, 232 e 223;

39 Grupo: 222.

Uma vez que já são conhecidas as estimativas das variâncias das estimativas dos parâmetros tem-se:

10 Grupo: $V(\widehat{Y})=0,7322 \sigma^{2}$ e portanto $\widehat{V}(\widehat{Y})=0,7322 s^{2}$

20 Grupo: $V(\widehat{Y})=0,5737 \sigma^{2}$ e portanto $\widehat{V}(\widehat{Y})=0,5737 \mathrm{~s}^{2}$

39. Grupo: $V(\widehat{Y})=0,4333 \sigma^{2}$ e portanto $\hat{\mathrm{V}}(\widehat{\mathrm{Y}})=0,4333 \mathrm{~s}^{2}$

Admitindo-se o nível de $95 \%$ de probabilidade e tomando $t=2,78$, os extremos dos intervalos de confiança são:

10. Grupo: $\widehat{\mathrm{Y}} \pm \mathrm{ts} \sqrt{0,7322} \Longrightarrow \hat{\mathrm{Y}} \pm 2,3788 \mathrm{~s}$

20. Grupo: $\widehat{\mathrm{Y}} \pm \mathrm{ts} \sqrt{0,5737} \Longrightarrow \hat{\mathrm{Y}} \pm 2,1056 \mathrm{~s}$

39. Grupo: $\hat{\mathrm{Y}} \pm \mathrm{ts} \sqrt{0,4333} \Longrightarrow \hat{\mathrm{Y}} \pm 1,8299 \mathrm{~s}$ 
No Del ineamento Duplo Composto Central Ortogonal:

Observa-se que os 29 tratamentos dados na Matriz X se subdividem em 5 grupos distintos, assim formados:

19. Grupo: 000, 400, 040, 440, 004, 404, 044 e 444;

20. Grupo: $111,311,131,331,113,313,133$ e. 333 ;

39. Grupo: 222;

49. Grupo: 022, 422, 202, 242, 220 e 224;

50 Grupo: 122, 322, 212, 232, 221 e 223.

Uma vez conhecidas as estimativas das variâncias das estimativas dos parâmetros tem-se:

\begin{tabular}{|c|c|c|c|c|c|c|}
\hline 10 & Grupo: & $\mathrm{V}(\widehat{\mathrm{Y}})$ & $=0,6356 \sigma^{2}$ & e portanto & $\widehat{\mathrm{V}}(\widehat{\mathrm{Y}})$ & $=0,6356$ \\
\hline 29 & Grupo: & $\mathrm{V}(\widehat{\mathrm{Y}})$ & $=0,1273 \sigma^{2}$ & e portanto & $\widehat{\mathrm{V}}(\widehat{\mathrm{Y}})$ & $=0,1273$ \\
\hline ? & Grupo: & $\mathrm{V}(\widehat{\mathrm{Y}})$ & $=0,1140 \sigma^{2}$ & e portanto & $\widehat{\mathrm{V}}(\widehat{\mathrm{Y}})$ & $=0,1140$ \\
\hline 0 & Grupo: & $\mathrm{V}(\widehat{\mathrm{Y}})$ & $=0,5059 \sigma^{2}$ & e portanto & $\widehat{\mathrm{V}}(\widehat{\mathrm{Y}})$ & $=0,5059$ \\
\hline & ru & $\mathrm{V}(\widehat{\mathrm{Y}})$ & $=0,1238 \sigma^{2}$ & e portanto & $\widehat{\mathrm{V}}(\widehat{\mathrm{Y}})$ & $=0,123$ \\
\hline
\end{tabular}


Admitindo-se o níve1 de $95 \%$ de probabilidade e tomando-se $t=2,10$, os extremos dos intervalos de confiança são:

10. Grupo: $\widehat{\mathrm{Y}} \pm \mathrm{ts} \sqrt{0,6356} \Longrightarrow \widehat{\mathrm{Y}} \pm 1,6742 \mathrm{~s}$

20. Grupo: $\widehat{\mathrm{Y}} \pm \mathrm{ts} \sqrt{0,1273} \Longrightarrow \widehat{\mathrm{Y}} \pm 0,7493 \mathrm{~s}$

39. Grupo: $\widehat{\mathrm{Y}} \pm \mathrm{ts} \sqrt{0,1140} \Longrightarrow \hat{\mathrm{Y}} \pm 0,7090 \mathrm{~s}$

49. Grupo: $\hat{\mathrm{Y}} \pm \mathrm{ts} \sqrt{0,5059} \Longrightarrow \hat{\mathrm{Y}} \pm 1,4936 \mathrm{~s}$

50. Grupo: $\widehat{\mathrm{Y}} \pm \mathrm{ts} \sqrt{0,1238} \Longrightarrow \widehat{\mathrm{Y}} \pm 0,7389 \mathrm{~s}$ 
59.

5. CONCLUSÕES

A metodologia de superfície de resposta, através da utilização de um modelo polinomial quadrático do delineamento duplo com posto central ortogonal e do delineamento composto central ortogonal,pa ra três fatores, levou aos seguintes resultados e conclusões:

1. As estimativas de todos os coeficientes do 19 e 20 graus, encontradas pelo método dos quadrados mínimos, são independentes da estimativa do coeficiente $a_{0}$ no d.c.c.o. e do $b_{0}$ no d.d.c.c.o., correspondentes à média.

2. As variâncias das estimativas dos termos quadráticos no delineamento d.c.c.o. são menores quando comparadas ao c.c.o., se gundo critérios de BOX e WILSON (1951) e de MYERS (1971). Esta propriedade é altamente vantajosa pois tais coeficientes 
60.

são diretamente responsāveis pela curvatura da função, que è responsável pela localização do ponto ótimo econômico.

3. Concluímos que o delineamento duplo composto central ortogonal com 29 pontos é mais eficiente que o composto central or togonal, pois possibilita o estudo de três fatores com maior nümero de níveis e gera variâncias menores das estimativas. 
6. BIBLIOGRAFIA

BOX, G.E.P. e K.B. WILSON, 1951. On The Experimental Attainment of Optimum Conditions. Journal of The Statistical Society, Londres, B13: $1-45$.

BOX, G.E.P., 1954. Exploration and Exploitation of Response Surfaces: So me General Considerations and Examples. Biometrics. 10: 16-60.

BOX, G.E.P. e J.S. HUNTER, 1957. Multi-Factor Experimental Designs for Exploring Response Surfaces. Ann. Math. Stat. 28: 195-241.

CAMPOS, H., 1967. Aspectos da Aplicação das Superfícies de Resposta a Ensaios Fatoriais $3^{3}$ de Adubação. Piracicaba, ESALQ/USP, 82 p. (Tese de Livre-Docência).

CONAGIN, A., J.P.N. JORGE e W.R. VENTURINI, 1969. Delineamentos Experí mentais Utilizáveis na Experimentação de Campo. In: REYNAERT, E. E., ed. La Investigación de Fertilidad de Suelos para la Producción en 1a Zona Templada. Montevideo, IICA Zona Sur. pp. 183-201. 
CONAGIN, A. e J.P.N. JORGE, 1979. Delineamento Duplo Composto Central com 29 Pontos. Bragantia, Campinas, 38: 217-235.

CONAGIN, A., 1982-A.Delineamentos Compostos Centrais Duplos. Bragantia, Campinas, 41: 35-48.

CONAGIN, A., 1982-B.Delineamentos Compostos Centrais Ortogonais, Rotacionais e Divisíveis em Blocos. Bragantia, Campinas, 41: 49-56.

COSTA, R.A. da, 1977. Funções de Produção Ajustadas a Ensaios Fatoriais $3^{3}$ de Adubação de Arroz. Piracicaba, ESALQ/USP, 80pp. (Disser- . tação de Mestrado).

DIXON, W.J. e F.J. MASSEY, 1951. Introduction to Statistical Analysis. Nova York, McGraw-Hi11. 370 p.

JORGE, J.P.N., 1980. Delineamento Guadalupe para Três Fatores, Analisa do Atravēs de Modelo de Regressão Polinomial Quadrática. Piracicaba, ESALQ/USP, 56 p. (Dissertação de Mestrado).

LIMA, A.R.C., 1980. Superfícies de Resposta em Experimentos Fatoriais $3^{3}$ Incompletos de Adubação NPK em Mandioca. Piracicaba, ESALQ/USP, 100 p. (Dissertação de Mestrado).

MONTEIRO, J.R.A., 1978. Comportamento de Funções de Produção em Ensaios Fatoriais $3^{3}$ de Adubação NPK em Amendoim no Estado do Maranhão. Piracicaba, ESALQ/USP, 77.pp. (Dissertação de Mestrado).

MYERS, R.H., 1971. Response Surface Metodology. Boston Allyn And Bacon. $243 \mathrm{p}$. 
NICOLELLA, G., 1981. O Uso de Superfícies de Resposta na Interpretação de Ensaios de Adubação NPK em Plantações de Cacau. Piracicaba, ESALQ/ USP, 91 p.. (Dissertação de Mestrado).

OLIVEIRA, L.M., 1974. Eficiência de Delineamentos para Ajustamento de Superfícies de Resposta. Piracicaba, ESALQ/USP, 61 pp. (Dissertação de Mestrado).

PIMENTEL GOMES, F. e H. CAMPOS, 1972. The Efficiency of Factorial $3^{3}$ Designs as Compared to a Central Composite Rotatable Design. Potash Review, Fevereiro.

VIEIRA, S., 1970. Aspectos das Funções de Produção Ajustadas aos Ensaios Fatoriais $3^{3}$ de Adubação. Piracicaba, ESALQ/USP, 165pp. (Fese de Doutoramento). 
64.

7. APEENDICE

Para exemplificar a aplicação da metodologia de super fície de resposta polinomial a dados provenientes de experimentos com os delineamentos composto central ortogonal (15 pontos) e o duplo composto central ortogonal (29 pontos), simulou-se um ensaio de adubação com $\mathrm{N}, \mathrm{P}$ e $\mathrm{K}$, em milho, cujos dados foram obtidos a partir da equação fundamental, de segundo grau, que representa uma boa produção de milho na região de Ribeirão Preto, Estado de São Paulo, onde foram estudados 50 ensaios apresentados em CAMPOS (1967).

A equação.é dada por:

$$
\begin{aligned}
\hat{Y}=5.915,1+ & 700,1 X_{1}+106,2 X_{2}+262,0 X_{3} \\
& -260,2 X_{1}^{2}-40,7 X_{2}^{2}-79,2 X_{3}^{2} \\
& -50,3 X_{1} X_{2}-64,7 X_{1} X_{3}+1,0 x_{2} X_{3}
\end{aligned}
$$


onde $\mathrm{X}_{1}, \mathrm{X}_{2}$ e $\mathrm{X}_{3}$ representam $\mathrm{N}, \mathrm{P}$ e $\mathrm{K}$, respectivamente.

Para facilitar a ortogonalização (diagonalização da matriz) faz-se a transformação:

$$
\begin{aligned}
\hat{Y}=\hat{\eta}_{0} & +700,1 x_{1}+106,2 x_{2}+262,0 x_{3} \\
& -260,2\left(x_{1}^{2}-1\right)-40,7\left(x_{2}^{2}-1\right)-79,2\left(x_{3}^{2}-1\right) \\
& -50,3 x_{1} x_{2}-64,7 x_{1} x_{3}+1,0 x_{2} x_{3}
\end{aligned}
$$

onde $\hat{n}_{0}=5.915,1+(-260,2-40,7-79,2)=5.535,0$

onde, finalmente a equação usada para ambos os delineamentos é:

$$
\begin{aligned}
\hat{\mathrm{Y}}=5.535,0 & +700,1 \mathrm{x}_{1}+106,2 \mathrm{x}_{2}+262,0 \mathrm{x}_{3} \\
& -260,2\left(\mathrm{x}_{1}^{2}-1\right)-40,7\left(\mathrm{x}_{2}^{2}-1\right)-79,2\left(\mathrm{x}_{3}^{2}-1\right) \\
& -50,3 \mathrm{x}_{1} \mathrm{x}_{2}-64,7 \mathrm{x}_{1} \mathrm{x}_{3}+1,0 \mathrm{x}_{2} \mathrm{x}_{3}
\end{aligned}
$$

Aos valores observados de produção, a partir dessa equação, foram adicionados erros provenientes de distribuição normal com desvio padrão $\sigma=684,78 \mathrm{~kg} / \mathrm{ha}$, tirados da Tabela de DIXON e MASSEY (1951). Foram simulados dados de produção, em quilogramas por hectare, tanto para o delineamento de 15 pontos como para o de 29, para uma repetição, somente. 
Os dados simulados de produção, relativos à aplicação dos tratamentos especificad@s, foram obtidos utilizando-se a matriz $\mathrm{X}$ das páginas 47 e 49, e são dados a seguir:

7.1. Exemplo Aplicado ao del ineamento de 15 pontos.

\begin{tabular}{|c|c|c|}
\hline Valor Simulado & Valor Estimado & Intervalo de Confiança \\
\hline$Y_{j}$ & $\widehat{\mathrm{Y}}_{\mathbf{j}}$ & $:$ \\
\hline $\mathrm{kg} / \mathrm{ha}$ & $\mathrm{kg} / \mathrm{ha}$ & \\
\hline $4.153,387$ & $4.593,024$ & $(2.964,179 ; 6.222,089)$ \\
\hline $4.791,066$ & $4.794,605$ & $(3.163,760 ; 6.421,670)$ \\
\hline $3.787,811$ & $4.012,805$ & $(2.383,960 ; 5.641,870)$ \\
\hline $5.598,756$ & $5.881,310$ & $(4.252,465 ; 7,510,375)$ \\
\hline $6.350,499$ & $6.317,544$ & $(4.688,699 ; 7.946,609)$ \\
\hline $5.084,266$ & $4.827,546$ & $(3.198,701 ; 6.456,611)$ \\
\hline $4.990,433$ & $4.676,387$ & $(3.047,542 ; 6.305,452)$ \\
\hline $6.198,942$ & $5.727,781$ & $(4.098,936 ; 7.356,846)$ \\
\hline $4.979,845$ & $4.681,611$ & $(3.239,848 ; 6.123,594)$ \\
\hline $5.503,677$ & $5.111,023$ & $(3.669,260 ; 6.553,006)$ \\
\hline $6.034,839$ & $5.274,272$ & $(3.832,509 ; 6.716,255)$ \\
\hline $5.718,203$ & $6.103,474$ & $(4.661,711 ; 7.545,457)$ \\
\hline $4.825,853$ & $5.305,502$ & $(3.863,739 ; 6.747,485)$ \\
\hline $4.189,602$ & $5.037,152$ & $(3.595,389 ; 6.479,135)$ \\
\hline $5.532,993$ & $5.396,137$ & $(4.143,305 ; 6.649,463)$ \\
\hline $77.740,173$ & $\Sigma \hat{Y}=77.740,173$ & \\
\hline
\end{tabular}


Utilizando a metodologia que se encontra em 4.1 obte mos as matrizes

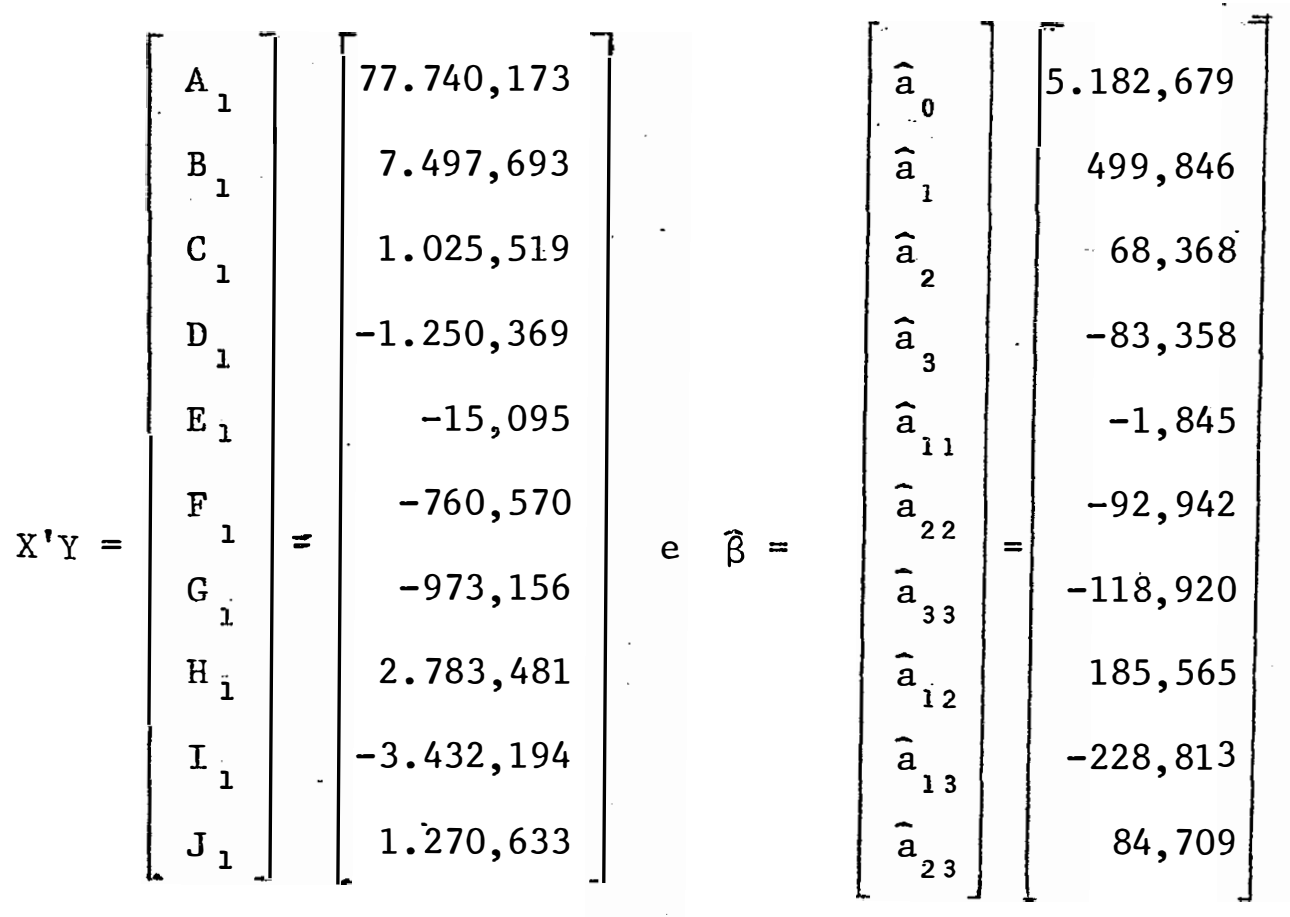

Aplicando a análise da variāncia aos dados do experimento, chega-se aos resultados que se seguem: 
68.

\begin{tabular}{|c|c|c|c|c|}
\hline Causas de Variação & G.L. & S.Q. & Q.M. & $F$ \\
\hline Média & 1 & $402.902 .299,80$ & & $608,059 * *$ \\
\hline Efeito $\hat{a}_{1}: N^{\prime}$ & 1 & $3.747 .695,75$ & $3747.695,75$ & 5,66 \\
\hline Efeito $\hat{\mathrm{a}}_{2}: \mathrm{P}^{\prime}$ & 1 & $70.112,58$ & $70.112,58$ & 0,11 \\
\hline Efeito $\hat{\mathrm{a}}_{3}: \mathrm{K}^{\prime}$ & 1 & $104.228,20$ & $104.228,20$ & 0,16 \\
\hline Efeito $\hat{a}_{11}: \mathrm{N}^{i \prime}$ & 1 & 27,85 & 27,85 & 0,00 \\
\hline Efeito $\hat{a}_{22}: P^{\prime \prime}$ & 1 & $70.688,72$ & $70.688,72$ & 0,11 \\
\hline Efeito $\hat{\mathrm{a}}_{33}: \mathrm{K}^{\prime \prime}$ & 1 & $115.727,33$ & $115.727,33$ & $0,17 * *$ \\
\hline Efeito $\hat{a}_{12}: N^{\prime} \times P^{\prime}$ & 1 & $516.517,88$ & $516.517,88$ & $0,78 \div \div$ \\
\hline Efeito $\hat{a}_{13}: N^{\prime} \times K^{\prime}$ & 1 & $785.330,00$ & $785.330,00$ & $1,19 \div *$ \\
\hline Efeito $\hat{\mathrm{a}}_{23}: \mathrm{P}^{\prime} \times \mathrm{K}^{\prime}$ & 1 & $107.633,89$ & $107.633,89$ & 0,16 \\
\hline Regressão & 10 & $5.517 .962,19$ & $551.796,22$ & $0,83 * *$ \\
\hline Resíduo & 4 & $2.650 .416,81$ & $662.604,20$ & \\
\hline $\mathrm{T} \circ \mathrm{t}$ a 1 & 14 & $8.168 .379,00$ & & \\
\hline
\end{tabular}

$$
\text { C.V. }=\frac{100 \times \mathrm{s}}{\widehat{\mathrm{m}}}=13,21 \%
$$

Com os elementos de $\widehat{\beta}$, pode-se escrever a equação polinomial de superfície de resposta

$$
\begin{aligned}
\hat{\mathrm{Y}}=5.182,678 & +499,846 \mathrm{x}_{1}+68,368 \mathrm{x}_{2}-83,358 \mathrm{x}_{3} \\
& -1,845\left(\mathrm{x}_{1}^{2}-1\right)-92,942\left(\mathrm{x}_{2}^{2}-1\right)-118,920\left(\mathrm{x}_{3}^{2}-1\right) \\
& +185,565 \mathrm{x}_{1} \mathrm{x}_{2}-228,813 \mathrm{x}_{1} \mathrm{x}_{3}+84,709 \mathrm{x}_{2} \mathrm{x}_{3}
\end{aligned}
$$


69.

cuja equação dada nas variāveis originais é:

$$
\begin{aligned}
\hat{Y}=5.396,085 & +499,846 X_{1}+68,368 X_{2}-83,358 X_{3} \\
& -1,845 X_{1}^{2}-92,942 X_{2}^{2}-118,920 X_{3}^{2} \\
& +185,565 X_{1} X_{2}-228,813 X_{1} X_{3}+84,709 X_{2} X_{3}
\end{aligned}
$$

7.2. Exemplo Apl icado ao Delineamento de 29 Pontos.

Para o delineamento duplo composto central ortogonal os valores de $x^{\prime}$ s são os da tabela que se encontra na página 49.

Os dados obtidos são: 
Valor Observado

$\mathrm{Y}_{\mathrm{ijk}}$

$\mathrm{kg} / \mathrm{ha}$

3. 715,553

$5.893,431$

$3.437,201$

$5.634,452$

$4.798,629$

$5.057,016$

$4.801,577$

$6.164,713$

$5.547,921$

$5.197,900$

$5.803,509$

$5.352,400$

$4.957,684$

$4.376,154$

$5.185,532$

$5.983,527$

$5.156,364$

$2.200,766$

$5.281,709$

5.967 .111

$6.578,578$

$5.313,493$

$6.181,009$

$5.830,565$

$6.467,009$

$3.664,099$

$5.136,296$

$5.621,877$

$6.448,610$

$\Sigma \mathrm{Y}=151.754,687$
Valor Estimado

$\hat{\mathrm{Y}}_{\mathbf{i} \mathbf{j k}}$

$\mathrm{kg} / \mathrm{ha}$

$3.683,100$

$5.553,686$

$3.225,762$

$5.739,382$

$4.578,000$

$5.272,425$

$5.100,147$

$6.437,645$

$4.752,766$

$5.175,596$

$4.726,939$

$5.621,354$

$5.756,254$

$5.750,201$

$5.394,601$

$6.129,938$

$5.568,318$

$3.196,888$

4.672., 768

$5.883,678$

$5.618,826$

$5.640,608$

$5.519,591$

$5.786,778$

$6.175,008$

$4.375,441$

$5.119,781$

5.721, 122

$5.578,027$

$\sum \widehat{Y}=151.754,687$
Intervalo de Confiança

$(2.536,661 ; 4.829,579)$

$(4.407,247 ; 6.700,165)$

$(2.079,323 ; 4.372,241)$

$(4.592,943 ; 6.885,861)$

$(3.431,541 ; 5.724,459)$

$(4.126,006 ; 6.418,924)$

$(3.954,708 ; 6.246,626)$

$(5.291,206 ; 7.584,124)$

$(4.239,680 ; 5.265,892)$

$(4.662,510 ; 5.688,722)$

$(4.213,849 ; 5.240,061)$

$(5.108,268 ; 6.134,480)$

$(5.243,168 ; 6.269,380)$

$(5.237,115 ; 6.263,327)$

$(4.881,515 ; 5.907,727)$

$(6.616,852 ; 6.643,064)$

$(5.082,829 ; 6.053,847)$

$(2.174,052 ; 4.219,764)$

$(4.166,804 ; 5.178,772)$

$(5.377,714 ; 6.389 ; 682)$

$(4.595,990 ; 6.641,702)$

$(4.617,772 ; 6.663,484)$

$(5.013,627 ; 6.025,595)$

$(5.280,814 ; 6.292,782)$

(5.152,424; 7.197,884)

$(3.352,605 ; 5.398,317)$

$(4.613,817 ; 5.625,785)$

$(5.215,158 ; 6.227,126)$

$(4.555,346 ; 6.601,058)$ 
78.

As matxizes $X^{\prime} Y$ e $\widehat{\beta}$ são, assim, formadas:

$\mathrm{X}^{\prime} \mathrm{Y}=\left[\begin{array}{c}\mathrm{A}_{2} \\ \mathrm{~B}_{2} \\ \mathrm{C}_{2} \\ \mathrm{D}_{2} \\ \mathrm{E}_{2} \\ \mathrm{~F}_{2} \\ \mathrm{G}_{2} \\ \mathrm{H}_{2} \\ \mathrm{I}_{2} \\ \mathrm{~J}_{2}\end{array}\right]=\left[\begin{array}{c}151.754,687 \\ 17.113,246 \\ 3.376,032 \\ 8.498,484 \\ -10.398,937 \\ 3.042,189 \\ -5.300,510 \\ 2.523,953 \\ -4.616,362 \\ 3.844,627\end{array}\right] \quad \hat{B}=\left[\begin{array}{c}\mathrm{b}_{0} \\ \mathrm{~b}_{1} \\ \mathrm{~b}_{2} \\ \mathrm{~b}_{3} \\ \mathrm{~b}_{11} \\ \mathrm{~b}_{22} \\ \mathrm{~b}_{33} \\ \mathrm{~b}_{12} \\ \mathrm{~b}_{13} \\ \mathrm{~b}_{23}\end{array}\right]=\left[\begin{array}{r}5.232,920 . \\ 590,112 \\ 150,208 \\ 293,051 \\ -275,572 \\ 80,618 \\ -140,464 \\ 87,033 \\ -159,185 \\ 132,573\end{array}\right]$.

Com os elementos de $\widehat{\beta}$ pode-se escrever a equação po linomial de superfície de resposta

$$
\begin{aligned}
\hat{Y}=5.232,920 & +590,112 x_{1}+130,208 x_{2}+293,051 x_{3} \\
& -275,572\left(x_{1}^{2}-1\right)+80,618\left(x_{2}^{2}-1\right)-140,464\left(x_{3}^{2}-1\right) \\
& +87,033 x_{1} x_{2}-159,185 x_{1} x_{3}+132,573 x_{2} x_{3}
\end{aligned}
$$

e que nas variāveis originais é:

$$
\begin{aligned}
\widehat{Y}=5.568,338 & +590,112 X_{1}+130,208 X_{2}+293,051 X_{3} \\
& -270,572 X_{1}^{2}+80,618 X_{2}^{2}-140,464 X_{3}^{2} \\
& +87,033 X_{1} X_{2}-159,185 X_{1} X_{3}+132,573 X_{2} X_{3}
\end{aligned}
$$


Anālise de variância:

\begin{tabular}{|c|c|c|c|c|}
\hline Causas de Variação & G.L. & S.Q. & Q.M. & F \\
\hline Mëdia & 1 & $794.120 .173,10$ & $794.120 .173,10$ & $1.545,29 \div *$ \\
\hline Efeito $\widehat{b}_{1}: \mathrm{N}^{\prime}$ & 1 & $10.098 .735,00$ & $10.098 .735,00$ & $19,65 \div$ \\
\hline Efeito $\widehat{b}_{2}: \mathrm{P}^{\prime}$ & 1 & $491.669,47$ & $491.669,47$ & $0,96 *$ \\
\hline Efeito $\mathrm{b}_{3}: \mathrm{K}^{\prime}$ & 1 & $2.490 .494,50$ & $2.490 .494,50$ & $4,85 * *$ \\
\hline Efeito $\widehat{b}_{11}: \mathrm{N}^{\prime \prime}$ & 1 & $2.865 .655,00$ & $2.865 .655,00$ & $5,58 \div \%$ \\
\hline Efeito $\widehat{b}_{22}: \mathrm{P}^{\prime \prime}$ & 1 & $245.254,97$ & $245.254,97$. & $0,48 *$ \\
\hline Efeito $\widehat{b}_{33}$ : $\mathrm{K}^{\prime \prime}$ & 1 & $744.528,69$ & $744.528,69$ & 1,45 \\
\hline Efeito $\widehat{b}_{12}: \mathrm{N}^{\prime} \times \mathrm{P}^{\prime}$ & 1 & $219.667,00$ & $219.667,00$ & 0,43 \\
\hline Efeito $\widehat{b}_{13}: \mathrm{N}^{\prime} \times \mathrm{K}^{\prime}$ & 1 & $734.855,19$ & $734.855,19$ & 1,43 \\
\hline Efeito $\widehat{b}_{23}: P^{\prime} \times K^{\prime}$ & 1 & $509.694,78$ & $509.694,78$ & $0,99 *$ \\
\hline Regressão & 10 & $18.400 .554,59$ & $1.840 .055,46$ & 3,58 \\
\hline Resíduo & 18 & $9.520 .141,91$ & $513.896,77$ & . \\
\hline $\mathrm{T} \circ \mathrm{t} a$ & 28 & $27.650 .696,50$ & & \\
\hline
\end{tabular}

C.V. $=\frac{100 \times s}{\hat{\mathrm{m}}}=13,09 \%$

Foram obtidos os intervalos de confiança das estimativas dos parâmetros, dados a seguir: 
Verifica-se que os intervalos obtidos no C.C.O. são de variação maior do que no D.C.C.O. mostrando assim que, os parâmetros do C.C:O. estão sujeitos a grande variação e, consequentemente, levando a uma estimativa de produção pouco digna de crédito, podendo in clusive ocorrer uma produção negativa nos ensaios de pouco rendimento. Foram obtidos, tambēm, os pontos de mäximo, de mínimo e de sela das produções observadas, utilizando-se da metodologia apre sentada em MYERS (1971).

Foram estudados 50 casos, que são dados a seguir: 
Para o C.C.o. Pontos de Máximo, de Mínimo, de Sela e produções.

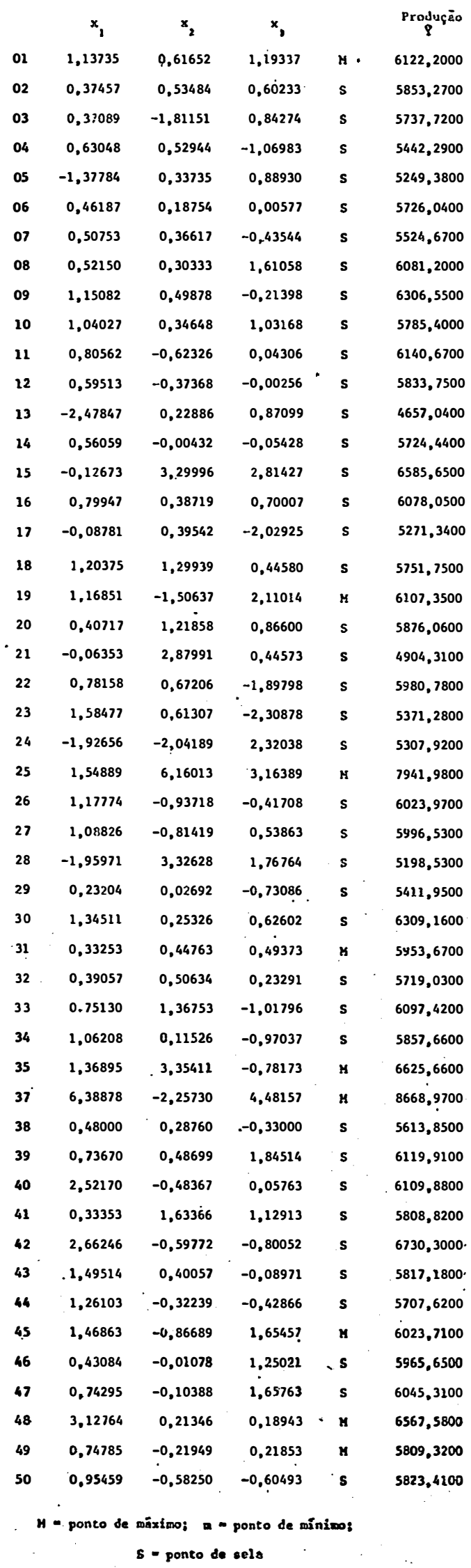


Para o D.C.C.O. Pontos de Máximo, de Mínimo, de Sela e produções.

\begin{tabular}{|c|c|c|c|c|c|}
\hline & $x_{1}$ & $x_{2}$ & $x_{1}$ & & $\underset{P}{\text { Produsão }}$ \\
\hline 01 & 1,13735 & 0,61652 & 1,19337 & M & 6122,2000 \\
\hline 02 & 5,29950 & 9,37775 & 4,14193 & $\mathbf{s}$ & 8657,1500 \\
\hline 03 & 0,53201 & 0,24278 & 1,52945 & M & 5998,4700 \\
\hline 04 & 0,33562 & 0,69685 & 3,07582 & $\mathbf{s}$ & 6244,7900 \\
\hline OS & 3,63889 & $-0,53914$ & $-4,08134$ & $M$ & 6465,7300 \\
\hline $06^{\circ}$ & 3,28983 & $-1,21033$ & $-0,52187$ & $\mathbf{s}$ & $6936 \dot{6}, 5700$ \\
\hline 07 & 1,93455 & $-0,10488$ & $-1,11827$ & $\mathbf{s}$ & 6207,3300 \\
\hline 08 & 2,30982 & 0,46606 & $-0,40963$ & $s$ & 6363,7600 \\
\hline 09 & 1,08710 & $-0,19593$ & 0,43778 & $\mathbf{s}$ & 5514,9800 \\
\hline 10 & 1,50863 & $-0,82288$ & 0,92635 & $\mathbf{s}$ & 6223,8600 \\
\hline Pl1 & 2.22454 & $-1,28333$ & 1,13370 & $\mathbf{s}$ & 6755,2700 \\
\hline 12 & 1,39329 & 0,10528 & 1,76465 & $M$ & 5938,4000 \\
\hline 13 & 1,49277 & 1,40977 & 0,87529 & $\mathbf{H}$ & 6098,2400 \\
\hline 14 & $-0,02524$ & 1,60102 & 1,00067 & $\mathbf{s}$ & 5768,6900 \\
\hline 15 . & 1,14331 & $-0,95484$ & 2,01362 & м & 6098,6300 \\
\hline 16 & 0,78784 & 2,91546 & 1,50238 & $M$ & 6294,7700 \\
\hline 17 & 0,21578 & 2,61423 & $-0,18293$ & $\mathbf{s}$ & 5702,5900 \\
\hline 18 & 2,01792 & 0,13745 & $-4,07874$ & $\mathbf{s}$ & 53790400 \\
\hline 19 & 0,10504 & 1,58649 & 0,57496 & $\mathbf{s}$ & 5928,9900 \\
\hline 20 & 1,20677 & 2,09788 & 0,07279 & $M$ & 6267,3400 \\
\hline 21 & 2,71712 & 2,35695 & $-2,02664$ & $\mathbf{s}$ & 6338,2100 \\
\hline 22 & 0,34120 & $-3,13072$ & 0,21535 & $\mathbf{s}$ & 5325,8700 \\
\hline 23 & 0,86919 & 1,26654 & 1,44011 & $M$ & 6155,3900 \\
\hline 24 & 1,20621 & $-0,69314$ & $-2,53769$ & $\mathbf{s}$ & 5132,1000 \\
\hline 25 & 0,87029 & 0,78566 & $-0,20335$ & $\mathbf{s}$ & 5961,4700 \\
\hline 26 & 0,57710 & 0,87139 & 1,43551 & M & 6016,4300 \\
\hline 27 V & 1,13525 、 & 0,79956 & $-0,84054$ & $\mathbf{s}$ & 5532,8100 \\
\hline 28 & 1,35057 & $-2,44081$ & $-1,87899$ & $\mathbf{s}$ & 5551,8500 \\
\hline 29 & 1,16503 & $-0,76969$ & $-0,50656$ & $\mathbf{s}$ & 5857,9000 \\
\hline 30 & 2,18306 & 2,44043 & $-0,33349$ & $\mathbf{s}$ & 6129,2800 \\
\hline 31 & 1,58914 & $-5,87609$ & 5,05710 & $M$ & 7658,5500 \\
\hline 32 & 0,32214 & $=0,93574$ & 1,71497 & $\mathbf{s}$ & 5782,3400 \\
\hline 33 & 0,42218 & 1,84139 & 0,13140 & $\mathbf{s}$ & 6039,8200 \\
\hline 36 & 0,37309 & 2,42340 & 0,88860 & $\mathbf{s}$ & 5960,1900 \\
\hline 35 & $-0,32705$ & $-2,43808$ & 2,00757 & $\mathbf{s}$ & 5276,0200 \\
\hline 36 & 0,87030 & $-1,75109$ & 0,30504 & $\mathbf{s}$ & 5771,9600 \\
\hline 37 & 2,18155 & $-1,63044$ & 5,62491 & $\mathbf{H}$ & 6921,6900 \\
\hline 38 & 0,95960 & 5,34633 & $-2,51366$ & M & 6282,2800 \\
\hline 39 & 1,12303 & 0,38904 & 0,05714 & $\mathbf{s}$ & 5870,9100 \\
\hline 40 & 1,32238 & 0,59803 & $-1,08894$ & $\mathbf{s}$ & 6059,4100 \\
\hline 41 & 0,77368 & 1,74852 & 1,40894 & $\mathbf{s}$ & 6201,4400 \\
\hline 42 & 1,39977 & 1.48403 & 1,89637 & $M$ & 6707,2700 \\
\hline 43 & 2,89591 & 1,77666 & 21227 & $\mathbf{s}$ & 6659,0300 \\
\hline 44 & 1,10454 & $-0,03887$ & 0,30265 & $M$ & 5876,2000 \\
\hline 45 & 0,70358 & 1,09741 & 0,58307 & $\mathbf{s}$ & 6001,3100 \\
\hline 46 & 1,20307 & 2,20359 & 1,07000 & s & 6115,4300 \\
\hline 47. & 1,36274 & $-1,87768$ & $-0,48094$ & $\mathbf{s}$ & 700 \\
\hline 48 & 1,39413 & $0,24 \dot{118}$ & 1,21860 & $\mathbf{S}$ & 6121,5100 \\
\hline 49 & $1,22780^{\circ}$ & 1,26978 & 1,97443 & $\mathbf{s}$ & 6265,4400 \\
\hline 30 & 1.89679 & $-1,22674$ & 0,53853 & $\mathbf{s}$ & 6365,9700 \\
\hline
\end{tabular}

